\title{
COMMUNITY RESILIENCE PLANNING GUIDE FOR BUILDINGS AND INFRASTRUCTURE SYSTEMS
}
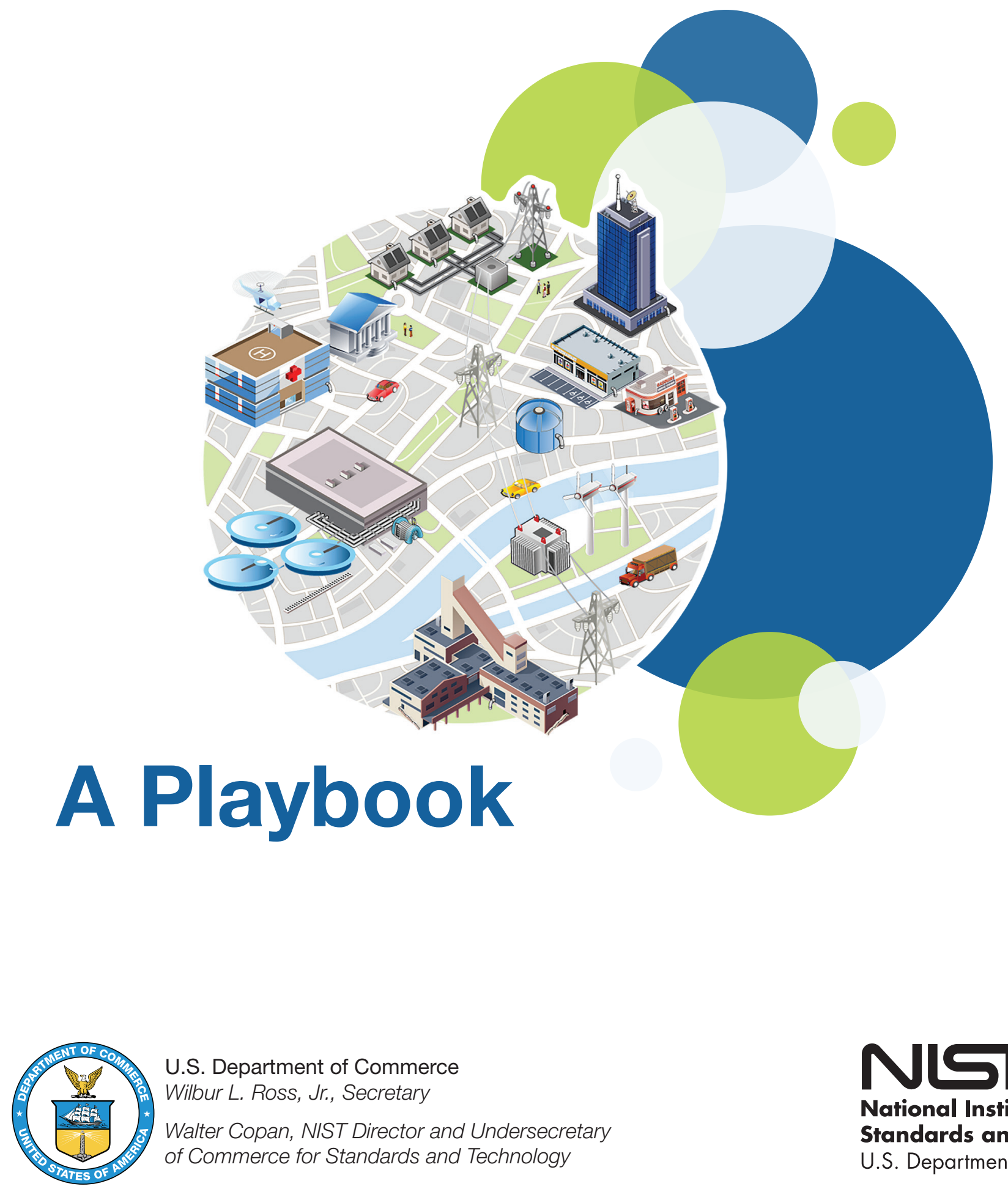

U.S. Department of Commerce

Wilbur L. Ross, Jr., Secretary

Walter Copan, NIST Director and Undersecretary of Commerce for Standards and Technology

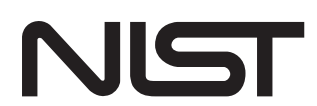

National Institute of Standards and Technology U.S. Department of Commerce 


\section{INTRODUGTION: \\ WHY PLANNING FOR IMPROVED RESILIENCE AT THE COMMUNITY LEVEL IS SO IMPORTANT AND HOW THIS PLAYBOOK CAN HELP}

With growing costs and disruptions from natural, technological, and human-caused hazards, many communities are placing higher priority on understanding and mitigating their vulnerability to, and increasing their ability to recover from, these hazards. They also need to manage their resources and ability to address these issues while considering other pressing demands.

A resilient built environment can:

- Result in less physical, economic, environmental, and social damage and impact;

- Support a fuller, more robust, speedier recovery;

- Preserve and enhance community functions, such as health and education;

- Require less time and money to be spent on relief efforts and repairs; and

- Promote "co-benefits," such as a livable, walkable community connected to the natural environment.

All communities can improve their resilience and capacity to protect lives, livelihoods, and the quality of life for their residents and businesses. The National Institute of Standards and Technology (NIST) Community Resilience Planning Guide for Buildings and Infrastructure Systems (Guide) recognizes that communities must prioritize their limited resources and that improving resilience is a process achieved over time.

The Guide's planning process provides a structured yet flexible way to set community-scale goals, align priorities and resources, identify key stakeholders, and develop plans for recovery of community functions. Community resilience planning can inform and integrate other community plans and also reduce conflicting goals between plans.

\section{WHAT IS COMMUNITY RESILIENCE? WHY DOES IT MATTER?}

Community resilience is the ability of a community to prepare for anticipated hazards, adapt to changing conditions, and withstand and recover rapidly from disruptions.

Residents rely on buildings and infrastructure systems for many functions and services that support the activities of daily living and that underpin the social and economic fabric of their community. By planning, prioritizing, and acting, communities can improve their resilience over time, in a cost-effective manner that is consistent with their long-term resilience goals.

If a disruptive event does occur, communities with resilience plans will be ready to respond, recover, and build back better - if rebuilding is necessary.

Communities that plan and carry out resilience strategies will be better prepared for future events, making the community more attractive to businesses and residents alike. 
This Playbook is intended to help communities more easily use the Guide and improve community resilience planning by addressing:

- The importance of connecting social and economic goals and services to the built environment (i.e., buildings and infrastructure systems or community lifelines).

- The interdependencies of social and economic functions with the built environment.

- The value and practical ways of planning for recovery - in addition to preparedness, design, mitigation, and emergency response.

- The benefits of a community-scale view of resilience.

\section{BASICS ABOUT THE NIST GUIDE}

The NIST Guide is based on the experience and expertise of community officials who have led planning for and responses to hazard events, as well as technical experts actively engaged in improving resilience across the country. The Guide encourages community leaders - government, private sector, and individuals - as well as community stakeholders to think more holistically and systematically about community resilience and the role of the built environment. It offers an approach to help communities integrate all of their community plans through community resilience planning and goals.

The Guide emphasizes the importance of interdependencies across the built environment, which includes buildings and infrastructure systems - especially those providing transportation, energy, communications, and water and wastewater services. The built environment supports vital social and economic functions such as shelter, food, education, healthcare, business and government. Community services and functions need to recover as quickly as possible, preferably within a specified period of time set by each community.

When recovery of key services and functions is delayed, community residents face increasing challenges to remaining in the community. Residents may ask questions like:

- "Is the hospital in full operation, especially for emergencies?"

- "Are the roads open for schools and businesses?"

- "Can I get food from the supermarket and cash from the ATM?"

\section{WHAT IS A COMMUNITY?}

In the NIST Guide, community refers to a place designated by geographical boundaries that functions under the jurisdiction of a governance structure, such as a town, city, or county.

\section{INFRASTRUCTURE SYSTEMS AND COMMUNITY LIFELINES}

While organized a bit differently, both infrastructure systems and community lifelines refer to physical networks that enable social functions that are essential to human health, safety, and economic security.

Infrastructure Systems: The NIST Guide and Playbook use Infrastructure Systems to describe physical networks (systems and facilities) that provide functions and services to the community. Infrastructure systems include transportation, energy, communications, water and wastewater systems. Building clusters (buildings with common functions) and supporting infrastructure systems are organized by functional categories, such as health, economy, education, or housing, for planning purposes. (See Step 2 for further discussion on building clusters and

Community Lifelines: FEMA uses Community Lifelines to describe the integrated network of assets, services, and capabilities that provide services to support the recurring needs of the community and enable all other aspects of society to function. Community Lifelines provide services that are used day-to-day to support the recurring needs of the community and enable all other aspects of society to function. Community lifelines comprise Safety and Security; Food, Water, and Shelter; Health and Medical; Energy (Power and Fuel); Communications; Transportation; and Hazardous Materials. 
Depending on an event's severity, many people and businesses may need assistance, possibly for an extended period of time.

Community resilience planning helps to determine which buildings and infrastructure systems support critical needs - and must be functional during and immediately after an event. Resilience planning also helps set phased recovery goals for the built environment in terms of community functions and when they should be restored in the subsequent days, weeks, and months.

\section{BEST PRACTICES FOR COMMUNITY RESILIENCE PLANNING}

Communities can best address common issues with planning processes by ensuring:

$>$ Broad stakeholder involvement.

> Visible support of the community's political leaders.

> Resilience goal integration into community comprehensive, land-use, hazard mitigation, economic, and other development plans.

$>$ Community plans that consists of prioritized, clearly identified, realistic resilience actions for implementation.

> Communities should develop plans that can be implemented and advance their resilience goals.

Resilience plans can be improved over time. Plans should address:

$>$ Prioritized gaps, vulnerabilities, and key issues.

> Appropriate levels of detail and accuracy based on available information and analyses.

The Guide applies to many types of hazard events and to large or small, urban or rural communities. There are many reasons for communities to start or improve their resilience planning, which the Guide can assist with, such as:

- To help them prioritize their use of limited resources as they make resilience-focused investments and administrative decisions.

- To more ably recover from hazard events by thinking through their goals, priorities, and current strengths and vulnerabilities, and asking informed questions.

- To accrue benefits of new investments and improvements in community spaces and infrastructure, even if a hazard event does not occur in the near future.

- To take advantage of the fact that resilience planning is most effective prior to a hazard event.

- To integrate well-developed resilience goals into other planning documents so that they will be better positioned to address opportunities to advance their resilience goals.

- To improve eligibility for funding from federal agencies (e.g., FEMA, HUD, EDA) and other sources.

The Guide tackles the resilience planning challenge by focusing on the built environment and how it supports community social and economic functions. The approach complements, but is broader than, the hazard mitigation planning conducted by communities to meet Federal Emergency Management Agency (FEMA) requirements for the Hazard Mitigation Assistance Grant, Flood Mitigation Assistance, and Building Resilient Infrastructure and Communities (BRIC) Programs. NIST's approach also is helpful for informing applications to, and management of, disaster mitigation and recovery grant programs of the Department of Housing and Urban Development (HUD), including the Community Development Block Grant Disaster Recovery Program, the Economic Development Administration (EDA), including the development of a Comprehensive Economic Development Strategy (CEDS). 
There is no one-size-fits-all approach to community resilience. Although many communities have common characteristics, each truly is unique. The NIST Guide seeks to convey the value of planning for resilience in a holistic, integrated fashion as part of a fully integrated community planning process using the six-steps summarized in the graphic.

\section{WHAT A RESILIENT COMMUNITY LOOKS LIKE}

In a perfectly resilient community, all buildings and infrastructure systems would recover rapidly from design level hazard events with little interruption in services. Buildings would remain usable, infrastructure systems would remain operational, and only a few days would be needed to clean up the mess and get back to normal operations.

In reality, buildings and infrastructure systems have been built over generations and are subject to aging and deterioration, changes in use and demands, and falling behind with regards to changing technologies, codes, and regulations. Frequently, a number of buildings and supporting infrastructure systems do not meet current minimum code requirements and are unlikely to contribute to community resilience in their existing condition.

Newer facilities and systems specifically designed for design level hazard events are more likely to contribute to a community's resilience if they require only minor repairs and can resume occupancy and operations shortly after the event.

Not every building and infrastructure system is needed immediately following a hazard event. But it is important that they be available when needed to support recovery. For example:

$>$ Hospitals and other emergency services are needed immediately but recreation centers may have delayed openings.

> Schools need to reopen quickly, but not before the emergency response period is over, roads are open for business, and families are settled.

By setting desired recovery time performance goals for building clusters based on needed social functions and then assessing their anticipated performance, a community can determine the required sequence of recovery activities for its built environment.

\section{SIX-STEP PROGESS TO PLANNING FOR GOMMUNITY RESILIENGE}

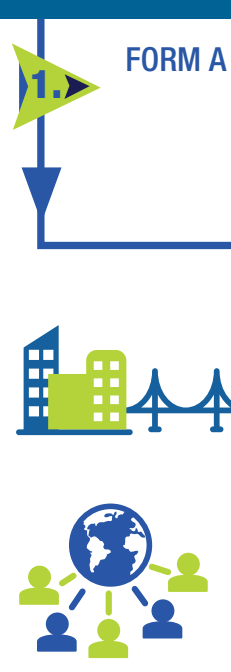

UNDERSTAND THE SITUATION

Social Dimensions

- Characterize social functions and dependencies

- Identify support by built environment

- Identify key contacts

Built Environment

- Identify and characterize built environment

- Identify key contacts

- Identify existing community plans

Link Social Functions and Built Environment

- Define clusters

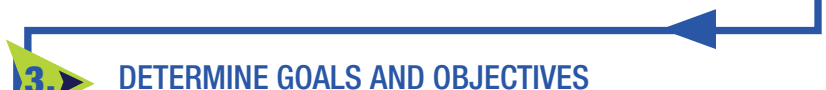

3.) DETERMINE GOALS AND OBJECTIVES
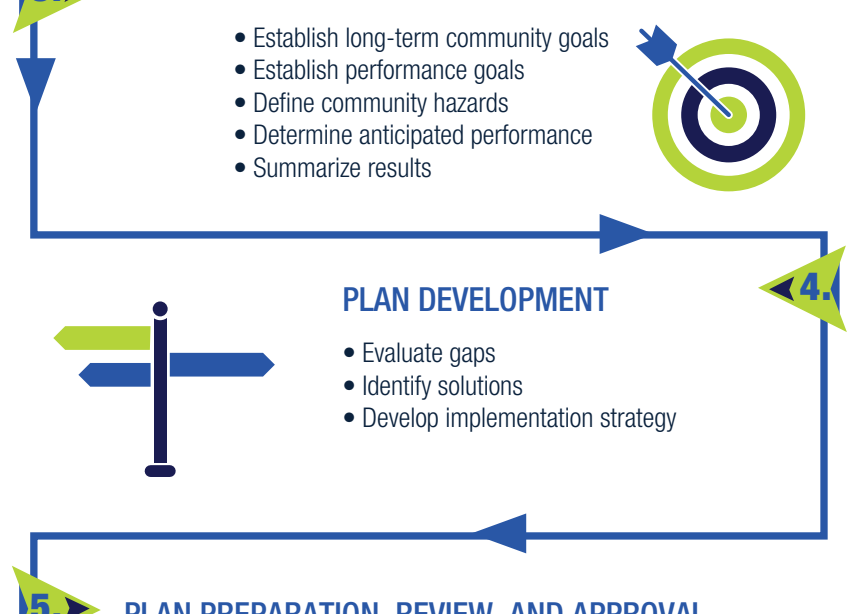

5.) PLAN PREPARATION, REVIEW, AND APPROVAL

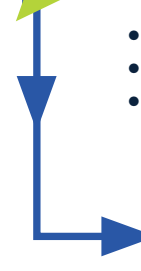

- Document plan and strategy

- Obtain feedback and approval

- Finalize and approve plan

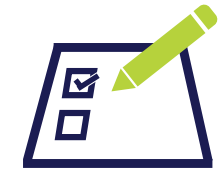

PLAN IMPLEMENTATION AND MAINTAIN

- Execute approved solutions

- Evaluate and update

- Modify strategy as needed 
Improvements to community resilience do not occur overnight and some priorities could take years or decades to fully be achieved. Still, meaningful progress can be made in shorter time frames. And there are always "low-hanging" options that can be considered once a community agrees on goals and directions. That's especially true if community resilience goals are integrated into all community plans.

The Guide encourages users to obtain input and support from public and private community stakeholders local government as well as individuals, community organizations, and service providers - to address recovery as well as hazard preparedness, response, mitigation, and adaptation goals. The Guide also helps communities review their current situation, including threats and vulnerabilities, and to identify performance goals and gaps in the performance of buildings and infrastructure. Then it assists communities in prioritizing and addressing those gaps through resilience goals and planning at the community scale.

All communities are encouraged to conduct the first three steps in the Guide. That will enable them to advance beyond the status quo by bringing key stakeholders together (Step 1), characterizing the community's current social and economic needs as well as its built environment (Step 2), and generating performance goals and gaps for building clusters to meet community functions and services (Step 3). Just asking the questions and considering the issues necessary to get to this point in the process can prove useful for communities exploring or embarking on the Guide's process.

\section{COMMUNITY RESILIENCE \& HAZARD MITIGATION PLANNING}

As of March 2020, 25,300 local jurisdictions in the U.S. have developed hazard mitigation plans to reduce risk from natural hazards and to ensure their eligibility for FEMA's Hazard Mitigation Assistance Grant Program. Hazard mitigation is considered to be sustained action taken to reduce or eliminate long-term risk to human life and property from hazards. The range of actions in hazard mitigation plans are similar to and complement those addressed in local plans and regulations that influence land use and development patterns, structure and infrastructure projects, natural systems protection, and education and awareness programs. Communities may use their hazard mitigation plan as a starting point for developing a community resilience plan.

Planning for community resilience emphasizes connecting mitigation and recovery phases of preparedness, but also includes response, protection, and prevention. Community resilience involves understanding how communities and their members' social and economic activities rely on the interconnected elements of the built environment and ensuring the community's goals for recovery of function of social and economic activities drive the prioritization and selection of risk-reducing activities. These activities span a range of constructed and administrative solutions (including those within a hazard mitigation plan). The process of developing hazard mitigation and community resilience plans are complementary.

The Guide process has two types of performance that

are evaluated for buildings and infrastructure systems: desired performance goals and anticipated performance. Desired performance goals are specified by the community in terms of time to recover functions for systems that are essential to the community and its recovery. It is important to note that desired performance goals are "hazard agnostic" because the need for community services and functions does not vary by hazard event. The anticipated performance is an assessment of the time to recover function performance expected for existing community systems if a hazard event occurred tomorrow. The difference between the desired performance (for all hazard events being considered) and the anticipated performance (for specified hazard events) identifies gaps that can negatively affect community recovery and long-term resilience.

Step 4 helps turn a community's enhanced understanding of how its social and economic functions rely upon the built environment and its interdependencies into a plan for moving ahead. After completing step 4, communities are strongly encouraged to move on to Step 5 (Plan Preparation, Review and Approval) and Step 6 (Plan Implementation and Maintenance). Details can be seen in the sections that follow each of the 6 steps and via associated links to worksheet templates (online) and the full Guide.

\section{PLAYBOOK USE AND APPLICATION}

This Playbook provides a practical, action-oriented aid to help communities follow the Guide's six-step process. It can assist communities seeking insights into resilience planning issues and help identify the most effective resilience- 
improvement projects. It also helps align community plans with resilience goals when seeking funds to support resilience activities. The Playbook can be used without expert assistance but also offers ways to engage experts in the planning and implementation stages.

This Playbook is designed to be a companion document to the Guide, with a focus on actions to accomplish in each step; it identifies the key concepts and approaches of the Guide. It can be especially useful for communities that wish to address only several of the steps - or simply to introduce the concept of the Guide's planning process and the interdependencies of buildings and physical infrastructure systems.

This Playbook is intended for communities of any size, at any stage of resilience planning, and a range of stakeholders:

- Elected or career officials in the public sector ranging from Emergency Services, Public Works, Water and Wastewater, Planning, Budgeting, Sustainability, and Citizen Engagement.

- Private sector businesses and industry including manufacturers as well as service providers and users.

- Non-profits and individuals, including volunteers.

- Generalists and technical experts, including consultants assisting communities with resilience planning and infrastructure projects.

\section{RESOURCES FOR THIS PLAYBOOK}

This Playbook is based on the NIST Guide and supplemental materials. It draws on the experience of several communities that have put the Guide to use. Users are encouraged to go to the full Guide for more details when desired. The Playbook also points to complementary materials developed by other federal agencies, non-profit organizations, and states and localities. Appropriate links to sections of the Guide and supporting materials including templates - are included in "Useful NIST Resources" at the end of each section and in the additional resources available on NIST's Community Resilience website.

\section{Q'Useful Resources}

NIST Community Resilience Group website:

https://www.nist.gov/topics/community-resilience

NIST Community Resilience Planning Guide:

https://www.nist.gov/topics/community-resilience/planningguide

NIST Community Resilience Planning Guide Brochure:

https://www.nist.gov/system/files/documents/2019/04/03/

nist community resilience 12 page brochure.pdf
Guide Brief 7 - Guide Use by All Community Types: https://nvlpubs.nist.gov/nistpubs/SpecialPublications/NIST. SP.1190GB-7.pdf

Guide Brief 15 - Additional Applications of the Community Resilience Planning Guide: https://www. nist.gov/publications/ guide-brief-15-additional-applications-community-resilienceplanning-guide

Playbook tables and templates: https://www.nist.gov/el/ communityresilience/community-resilience-planning-guideplaybook-templates-additional-resources 


\section{1. $>$ STEP 1: FORM A GOLLABORATIVE PLANNING TEAM}

\section{Objective}

Form a collaborative planning team to lead the development of a community resilience plan that will be informed and supported by key decision-makers, community leaders, and stakeholders across the public, non-profit, and private sectors.

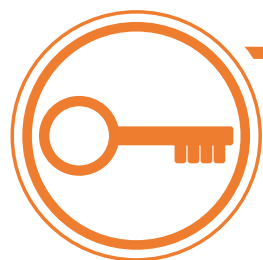

\section{Key Take-Aways}

A diverse and representative planning team is an important factor for a robust and successful community resilience plan.

- The resilience team representatives should reflect the community's composition, culture, and range of planning topics.

- Community engagement and buy-in are vital to success, including input from diverse and under-represented groups.

- Teams should include stakeholders across the public, non-profit, and private sectors, such as: government, utilities, businesses, schools, hospitals, and other key organizations and service providers.

\section{运 Actions to Accomplish}

1-1: Identify resilience leader for the community.

1-2: Identify team members, and their roles and responsibilities.

1-3: Establish the scope of the planning effort.*

1-4: Identify key public and private stakeholders.

* This new action item has been added to those listed in the NIST Guide. 


\section{PARTNERING FOR SUCCESS}

Local government is the logical convener of community resilience planning initiatives, although stakeholders and champions may come from other non-governmental organizations or regional government groups. The most effective resilience planning efforts are championed by a collaborative planning team that provides leadership throughout the process and engages stakeholders and the broader community.

There are many ways to design and operate a planning team. Team representatives should reflect the composition, culture, and range of planning topics in their communities, including recent, ongoing, or planned initiatives that relate to resilience.

The planning team should consist of local representatives who understand the value of community resilience planning, are committed to the process, and are able to champion resilience and engage the relevant stakeholders.

Beyond the planning team, public and private owners and operators of buildings and infrastructure systems, leaders of organizations, and community members should be aware of the resilience planning effort. They may be involved as advisors or help with specific tasks.

\section{COMMUNITY RESILIENCE LEADER}

Action 1-1: Identify a resilience leader for the community. A resilience leader is typically identified by the local governing authority or body to promote and coordinate community resilience.

A resilience leader serves as the community official for resilience efforts and coordination with elected community leaders and key community stakeholders. Identification and recruitment of a collaborative planning team begins with a resilience leader who directs the process, provides continuity, elevates the importance of resilience, convenes stakeholders, communicates effectively, and engages public support. A community resilience leader may be a Chief Resilience Officer (CRO), sustainability office head, emergency management professional, city planner, or other official with qualifications to advance community resilience.

\section{THE ROLE OF THE COMMUNITY RESILIENCE LEADER AND ELECTED OFFICIALS (ACTION 1-1)}

Successful community resilience efforts require a resilience leader who has political support for the planning and implementation process. Elected leaders endorse and act on recommendations of the planning effort that lead to greater community resilience.

Resilience leaders communicate the goals and objectives of the resilience planning effort to community members, businesses, and other stakeholders and encourage their support and participation in the planning effort and eventual implementation. They can elicit ideas and information from those who might otherwise not contribute.

Resilience leaders inform elected leaders of findings, issues, and decision points during the planning process. Dialogue with elected leaders is an essential part of the planning process to obtain important feedback on priorities and funding. 


\section{FORMING THE COLLABORATIVE PLANNING TEAM}

Action 1-2: Identify collaborative planning team members and their respective roles and responsibilities. Key public and private stakeholders should be identified who represent community interests on the core and broadened planning teams, with defined roles, responsibilities, and expectations for serving on the team.

There are multiple options for collaborative planning team members, and the composition of community interests and representative stakeholders will vary by community. A team that encompasses key decision-makers, community leaders, and stakeholders across the public, non-profit, and private domains is more likely to develop a community resilience plan that reflects the interests and needs of all stakeholders and will be supported for implementation. A diverse team can strategically engage relevant community stakeholders who have an interest in or impact on resilience planning efforts.

Considerations for identifying community resilience planning team members and key stakeholders are provided below, using the roles illustrated in Figure 1-1.

A-2 Terms To Know...

Collaborative planning team: A resilience planning group that works together with all key stakeholders to forge a fact-based, prioritized plan that can be implemented to improve community resilience. The team members collectively represent community interests rather than solely representing their organizations or sectors.

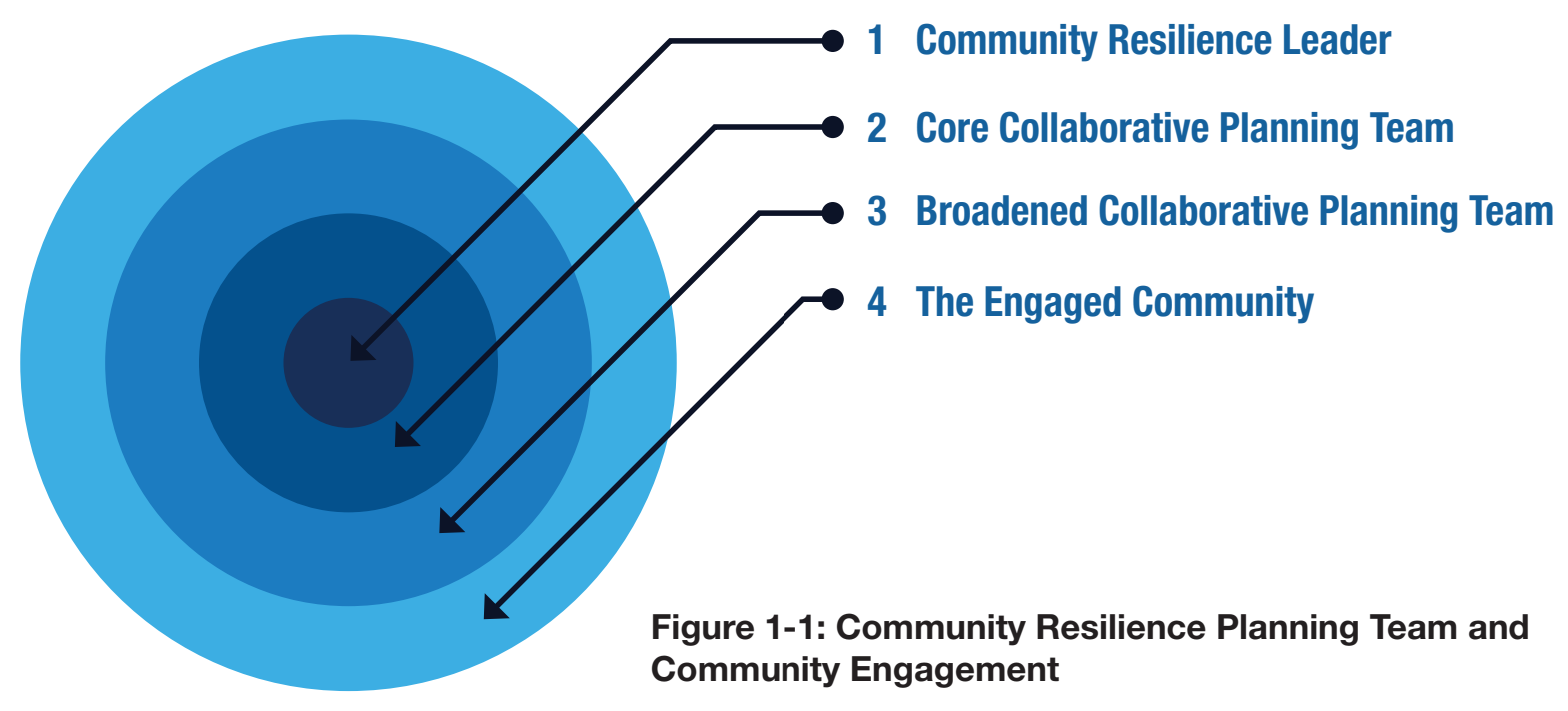

1. The community resilience leader communicates the goals and objectives of the resilience planning effort to community members and stakeholders and encourages their support and participation in the planning effort and its implementation. The community resilience leader may establish a core collaborative planning team.

2. The core collaborative planning team should have key representatives for local government functions such as: community planning, economic development, public works, engineering, emergency services, building and permitting, health and human services, housing, education, and sustainability. A core team can promote an efficient launch and develop an outline or draft of the proposed scope of the resilience effort. The core team can also identify others who should be brought onboard to form the broadened collaborative planning team and stakeholders who should be kept informed or made partners during the process. 
3. The broadened collaborative planning team may include external stakeholders who can contribute to community resilience, such as county, state, or federal agencies that manage facilities or infrastructure in the community or provide funding for resilience plans and projects. Team members may include representatives from utilities, schools, hospitals and other service providers along with residents' interest groups. Additionally, consultants or universities with special expertise, such as meteorological and climate trends or social vulnerabilities, may provide input.

4. The engaged community includes agencies, organizations, and groups not represented on the planning team that still need to be informed of progress and/or consulted for input on options and proposals. Although often not part of the planning team, the engaged community should be included from the start of the planning process. The early phases of planning may proceed more quickly without broad input - but the resulting plans may lack robustness and be based on ill-supported assumptions. Inclusiveness will help ensure approval and support for implementation.

Using the Guide Templates. Tables 1-1 to 1-3 and Template 1-1's tables provide examples of planning team members and their roles from local government, businesses and service professionals, and volunteer organizations. Planning teams should include existing groups or committees, such as Local Emergency Planning Committees (LEPCs), Voluntary Organizations Active in Disaster (VOADs), and sustainability, energy, and environment committees.

It may not be practical to include a representative from each local government department or private institution on the planning team. In that case, consider a representative for several offices or institutions (e.g., public works, local hospital association). One example is to have a single leader who is knowledgeable about community mitigation, response and recovery plans.

Tables 1-1, 1-2, 1-3. Examples to Help Form a Collaborative Planning Team (Action 1-2) Table 1-1. Local Government Stakeholders Who Could Be Included on Planning Team (Action 1-2)

\begin{tabular}{l|l}
$\begin{array}{l}\text { Office of the Chief Executive (e.g., } \\
\text { Mayor) }\end{array}$ & $\begin{array}{l}\text { Provides leadership, encourages collaboration among departments, and serves as the link } \\
\text { to stakeholders in organizing, compiling, and vetting the plan throughout the community. }\end{array}$ \\
\hline $\begin{array}{l}\text { Public Works Department, Facilities, } \\
\text { Plant Operations, General Services }\end{array}$ & $\begin{array}{l}\text { Responsible for planning, constructing, and maintaining publicly owned buildings, } \\
\text { transportation, and infrastructure, and identifies emergency response and recovery routes. }\end{array}$ \\
\hline Planning Department & $\begin{array}{l}\text { Identifies pre-event land use and mitigation opportunities and post-event recovery } \\
\text { opportunities that will improve the city's layout and reduce vulnerabilities. }\end{array}$ \\
\hline $\begin{array}{l}\text { Board of Education, Trustees and } \\
\text { Regents, School District, Education } \\
\text { Department }\end{array}$ & $\begin{array}{l}\text { Represents all levels of education and clarifies the system's tolerance for disruptions and } \\
\text { its ability to operate under temporary conditions. }\end{array}$ \\
\hline
\end{tabular}

See Website for Complete Table

\section{Table 1-2. Possible Business and Service Professionals for the Collaborative Planning Team (Action 1-2)}

\begin{tabular}{l|l}
$\begin{array}{l}\text { Chamber of Commerce and Industry } \\
\text { Associations }\end{array}$ & $\begin{array}{l}\text { Represents business and industry interests and includes leaders who will bring a clear } \\
\text { perspective on the economic impacts of potential disasters as well as resilience plans. }\end{array}$ \\
\hline $\begin{array}{l}\text { Developers, Building Owners, and } \\
\text { Managers }\end{array}$ & Provides building and housing owners' perspective on resilience and recovery. \\
\hline Utility Providers & Includes communications, power, transportation, and water, wastewater providers. \\
\hline Health, Healthcare Coalitions & $\begin{array}{l}\text { Includes public health officials, providers of acute, sub-acute, rehabilitation, mental health, } \\
\text { behavioral, and end-of-life care. }\end{array}$ \\
\hline
\end{tabular}

See Website for Complete Table 
Table 1-3. Possible Community and Volunteer Organizations for the Collaborative Planning Team (Action 1-2)

Non-Governmental Organizations (NGOs)

Voluntary Organizations Active in Disaster (VOADs)

Community Associations
Brings members' concerns to governments, advocates for and monitors policies, and encourages participation in resilience-related efforts.

Serves as a primary forum where organizations share knowledge and resources throughout the disaster preparedness cycle to help survivors and their communities.

Provides neighborhood and resident views, including homeowners, renters, and vulnerable populations.

See Website for Complete Table

\section{DETERMINING THE PLAN'S SCOPE}

Action 1-3: Establish the scope of the planning effort. Deciding on the scope of the resilience planning effort will play a big role in determining its success.

Determining the scope of the community resilience plan is key to defining success and setting expectations for community engagement and implementation of the plan - and ensures adequate representation on the planning team. The scope should consider factors such as what elements of the built environment will be included (e.g., government buildings and facilities, privately owned facilities) and associated stakeholders, and social and economic functions supported by the selected infrastructure. It also should take into account the users or stakeholders who rely on the services provided by these facilities. Considerations for the planning team could include:

- Prevailing hazards and chronic stressors. A FEMA hazard mitigation plan approach may provide a list of natural hazards for consideration. The team can leverage the information from the FEMA-approved mitigation plan and should decide whether it will address one or multiple prevailing hazards, or perhaps chronic stressors like increasing temperatures. The team may determine that certain hazards are out of scope because they are unlikely or because their potential impact might be so great that they are impractical to plan for from the standpoint of recovery.

- The elements of the built environment. The team may decide to address government-owned buildings for the first phase of its resilience planning effort. Considering this smaller subset may be easier for the team, but there are trade-offs - including the more limited view of resilience and implications for the community's ability to deal with and recover from a hazard event. The planning team should consider if privately owned and managed elements of the built environment (e.g., electrical infrastructure) should be included to ensure relevant private sector organizations' input are solicited (related to Action 1-4). In any case, if a community is conducting resilience planning while updating their hazard mitigation plan for FEMA, they may need to include all buildings and infrastructure systems deemed critical by the community.

- Concurrent updates of community plans. There are benefits in explicitly coordinating resilience planning with other planning efforts involving or led by the community - for example, comprehensive plans, economic development plans, emergency management plans, and continuity of operations plans, as well as sustainability or transportation planning efforts.

\section{ENGAGING PUBLIC AND PRIVATE STAKEHOLDERS}

Action 1-4: Identify key public and private stakeholders. The collaborative planning team should identify key stakeholders of public and private organizations, including infrastructure owners and operators and utility service providers.

When the planning team collaborates with public and private stakeholders, it improves understanding of the community's situation, gains community support for goals, identifies gaps and inconsistencies, and provides information for prioritizing solutions. A planning team member may be designated to lead engagement and collaboration with public and private organizations and individuals. 
Public and private stakeholders should be engaged to understand issues and identify local priorities, constraints, points of cooperation, and potential conflicts for community resilience plans. Additionally, stakeholders will be able to make informed decisions on the operation, maintenance, upgrade, and replacement of their systems in accordance with community resilience plans and their business objectives.

Considerations for engaging community stakeholders include:

- Support of key stakeholders: Socialize resilience plans in the community and with centers of community influence (government and private sector) to build support and understanding before publicly initiating the planning effort. Don't surprise anyone!

- Continuous community engagement: Continuous and active community outreach and engagement via workshops, briefings, collaborative online dialogues and tools, or focus groups - should be conducted throughout the planning and implementation process.

- Coordinator for community engagement: Appointing a team member to coordinate stakeholder engagement will help ensure representative inclusion of varied views. External or public affairs officers may be well positioned to serve in this role.

- Data management and sharing: When needed, a cooperative arrangement with private stakeholders that addresses concerns about information exchange and security for resilience planning can improve collaboration and access to critical information.

- Other resilience perspectives: Infrastructure stakeholders (e.g., communications, power, transportation, water and wastewater) may need to address resilience from a regional perspective of services and requirements from federal or state regulations.

\section{ENGAGEMENT WITH RESILIENCE STAKEHOLDERS (ACTION 1-4)}

Community engagement is essential to successful community resilience planning and implementation. Local champions can be influential in rallying the community around planning for resilience.

Local champions who are closely connected and engaged with neighborhood, business, or community groups or who are actively engaged in other community-based activities are important contributors. Beyond providing content and perspective, they can advocate for support from, and participation by, other community stakeholders. They can also encourage community groups with diverse and traditionally underrepresented views and experiences to participate.

Have a plan for reaching out to and engaging the broader community early in the process to avoid becoming insulated. Engagement, which is more substantial than outreach, is critical to the community providing input and building support for planning and implementation. Supplement planning team meetings with active community outreach and engagement - via workshops, briefings, collaborative online dialogues and tools, or focus groups. Template 1-2 can assist the planning team with stakeholder engagement planning. 


\section{COLLABORATIVE PLANNING TEAMS: DIVERSE APPROACHES}

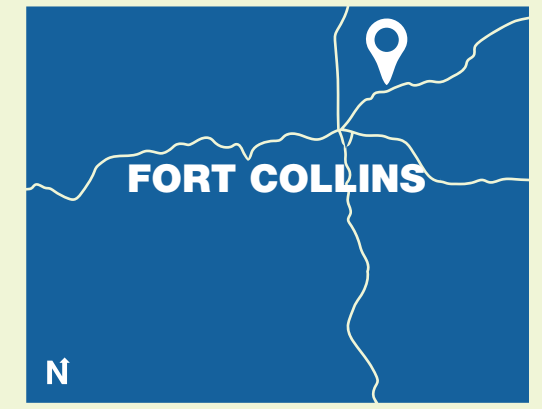

Fort Collins and Larimer County (CO) collaborated to implement the first four steps in the NIST Guide as part of the Department of Homeland Security (DHS) Regional Resilience Assessment Program (RRAP), with support from Idaho National Laboratory. A collaborative planning team was led by an Emergency Management Coordinator from Larimer County and supported by the Emergency Management Director of Fort Collins. Team members included representatives from the Fort Collins Department of Planning, Development, and Transportation, Fort Collins Utilities - Water and Power \& Light, and the Fort Collins Office of Social Sustainability. The effort engaged community stakeholders from four Social Functions identified in the NIST Guide (education, health, government, and nongovernmental organizations providing shelter) and four Utility Groups (water, wastewater, power, communications).

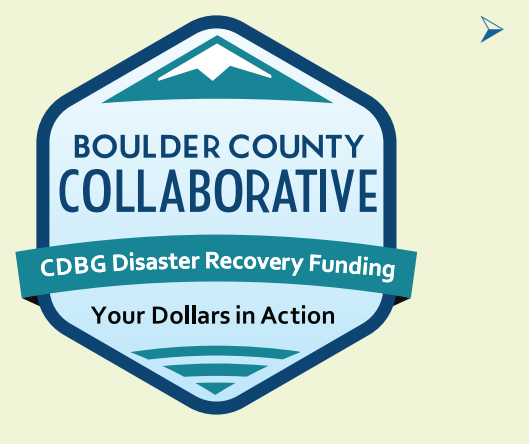

The Boulder County Collaborative (CO) began its work as part of a coalition of eight local governments in response to planned funding from the U.S. Department of Housing and Urban Development to the most pressing housing and infrastructure needs in the state. Using the NIST Guide process, the BCC held a series of workshops from November 2015 through March 2016 with a broad group of stakeholders, with focus groups that included regional utility and service providers. A training workshop also was conducted. The resulting standard draws on and complements the Colorado Resilience Framework that already had been published. The project's Collaborative Planning Team was led by the City of Longmont and included representatives from the Boulder County Collaborative's

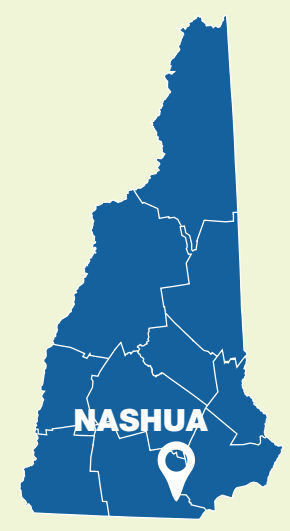
participating governments, utility service providers, the State of Colorado, HUD, local emergency response organizations, neighborhood resource associations, and interested community members.

For its Resilient Nashua (NH) initiative, led by the city's Office of Emergency Management, Nashua established a diverse Collaborative Planning Team, described by the project lead as "interested citizens to the city engineer, the soup kitchen to the Country Club." Nashua complemented the planning team with a steering committee and met with existing community groups and individuals in workshops as well as one-on-one sessions to ensure solid input and two-way communications. The effort was initiated with scoping meetings held with city departments.

\section{QUUseful NIST Resources}

GB 14 - Forming a Collaborative Planning Team and Engaging the Community:

https://www.nist.gov/publications/guide-brief-14-forming-collaborative-planning-team-and-engaging-community

Playbook tables and templates: https://www.nist.gov/el/communityresilience/community-resilience-planning-guide-playbooktemplates-additional-resources 


\section{Objective}

Gather information about the community's social and economic functions, buildings and infrastructure systems, and their interdependencies.

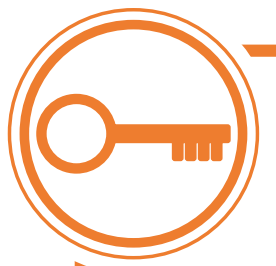

\section{Key Take-Aways}

- The community's social and economic functions and institutions drive the needs of the built environment.

- Identifying building clusters that support social and economic functions helps determine actions to improve resilience and set priorities.

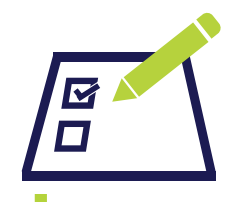

\section{Actions to Accomplish}

$\square$ 2-1: Assess existing community plans.

$\square$ 2-2: Characterize community members and their needs.

$\square$ 2-3: Characterize the community's social functions and dependencies.

$\square$ 2-4: Characterize the built environment.

$\square$ 2-5: Link social functions to the built environment. 


\section{BUILD COMMUNITY RESILIENCE ON EXISTING PLANNING EFFORTS}

Action 2-1: Assess existing community plans. The planning team should gather existing community planning documents and review their scope, goals and objectives, timeframes, and actions that relate to community resilience. The team also should consider upcoming planning initiatives.

In order to conduct effective resilience planning, a community needs a solid understanding of its population, social and economic functions and institutions, and their dependence on buildings and infrastructure, particularly in times of disruption due to hazard events. The actions in this step can promote a comprehensive understanding of community characteristics, needs, and vulnerabilities.

Most communities have multiple planning documents that incorporate their views of the future and drive priorities. These plans can provide a base set of information to identify opportunities to improve community resilience.

Documents may include comprehensive plans, general plans, land use plans, economic development plans, hazard mitigation plans, local pre-disaster recovery plans, sustainability plans, etc. Assessing these documents through a resilience perspective will help the team to better understand the full range of community needs, priorities, and gaps, as well as identify conflicts between plans. It can also be useful to identify when the plans will next be updated, as updates are good opportunities to incorporate resilience goals into plans.

Assessing existing plans helps stakeholders to understand that community plans need to be integrated and that they may impact one another through unintended conflicts or gaps. For example, when Fort Collins, CO, began its work, the planning team identified 27 plans produced by the city. All were reviewed to understand the city's long-term goals for development and inform the resilience planning process using the Plan Integration for Resilience Scorecard (PIRS) method. Continuity of operations plans were included in the review to understand the desired performance for covered facilities if a hazard event were to happen. In Nashua, $\mathrm{NH}$, the team reviewed all relevant policies and recommendations found in over 50 community plans. This process also identifies information already collected that can be used in later steps.

\section{RESILIENCE SCORECARD HELPS COMMUNITIES INTEGRATE PLANS (ACTION 2-1)}

The Plan Integration for Resilience Scorecard (PIRS) method is helping communities to integrate all their plans - like those for transportation, parks, economic development, hazard mitigation, emergency management and comprehensive land use - so that the plans work together to reduce vulnerability to hazards. For instance, a city's hazard mitigation plan may call for acquisitions and buy-outs in high-hazard areas, while its comprehensive land use plan may set goals to increase investments in the same location. Such plans are not only incompatible, but actively increase vulnerability. PIRS, developed by the Institute for Sustainable Communities at Texas A\&M University, walks users through a process that (1) evaluates community plans with respect to hazard risk and how well they target areas of the community that are most vulnerable, (2) identifies when and where those plans are in conflict, and (3) resolves those conflicts across plans to reduce hazard vulnerability.

\section{CHARACTERIZE THE COMMUNITY'S SOCIAL DIMENSIONS}

The collaborative planning team should assess the community's social institutions and built environment, focusing on their role and importance in resilience in the face of hazard events. They should consider different kinds of vulnerabilities and the needs of the entire population - remembering that all parts of the community are likely vulnerable in some ways. This helps the team to spot potential gaps in services, as well as to link vital services to relevant infrastructure and buildings. Template 1-1, Table 1-5 suggests potential members of a social dimensions task group. 
Actions 2-2 to 2-5 describe the steps of information collection necessary to develop a comprehensive understanding of the connection between the community's social dimensions and its built environment.

Action 2-2: Characterize community members and their needs. The planning team should collect information that provides a data-informed perspective on the community's population and contextual factors, including demographic, social, and economic factors that are important to the community's residents, organizations, and businesses.

Community members' present and future needs can be informed with data on population demographics, economic indicators, social vulnerabilities, and social capital. Demographic information can include age, health, education, income, employment, housing status, language, cultural background, and vulnerable populations (e.g., those with medical needs, low income households, non-English speaking populations, and individuals with limited mobility). Links for publicly available data to characterize the population are listed in Guide Brief 1 - Characterize the Population.

Understanding a community's vulnerable populations' needs, expectations, and reliance upon various community social functions leads to a more inclusive, comprehensive, and respectful resilience planning process. Communities should determine the needs of its most vulnerable populations, including those who may be underrepresented in government decision-making organizations, and ensure their perspectives and needs are reflected in resilience efforts and projects. This information will be especially useful in Step 4 - Plan Development. These vulnerable populations may have differing needs and require unique solutions.

\section{CONSIDER COMMUNITY MEMBERS (ACTION 2-2)}

\section{Demographics}

$>$ Are there geographic concentrations of populations, such as low-income households, older adults (ages 65+), individuals living with disabilities, and others who may need additional resources or assistance to deal with a hazard event?

$>$ If so, where are they located? How might their location further increase their vulnerabilities in the event of a disaster?

$>$ Is there a substantial non-English-speaking population in the community?

$>$ To what extent do residents have access to transportation in an emergency? Are there residents without the ability to evacuate?

$>$ What modes of public communication are needed to reach all residents? Broadcast and radio news, printed publications, online sources, public meetings, etc.?

See Guide Brief 14.

\section{Vulnerable populations}

> Vulnerable populations may include individuals, families, households, or non-household units with lower incomes, older adults, renters, those with limited mobility, individuals who do not speak or read English, those with limited transportation options.

$>$ The locations where these individuals live and work, and the community services they rely upon, can be identified through connections with individuals and organizations supporting vulnerable populations.

> Some populations may be more at risk because of their physical location - for example, living in a flood-prone area, residing in older or poorly maintained housing that may not be adequate for sheltering in place, or lacking means to evacuate.

$>$ Needs for public transportation and other systems may increase during evacuations or recovery following a hazard event.

> If a community's non-English-speaking population is projected to increase, this may affect plans for communications related to hazard mitigation and other resilience efforts. 
Data and input on community demographics and needs may be obtained from research centers, chambers of commerce, regional planning organizations, consulting firms, institutes of higher learning, faith-based institutions, and other organizations with data and/or analysis capabilities. Carrying out this step may call for assistance from local and regional entities, such as city or county planning departments, that have expertise accessing, providing, and interpreting social and economic data. Census data can be very helpful as well.

The planning team may also find it helpful to invite individuals with this expertise to serve as formal members of the social dimensions task group. Local colleges or universities can be ideal contributors or provide referrals.

Action 2-3: Characterize the community social functions and dependencies. The planning team should inventory and describe the various social dimensions of the community and the functions provided for residents, including vital services, important social and economic institutions, and characteristics that make the community desirable to residents and businesses.

Identifying social functions and dependencies, as well as key contacts or representatives who can provide information about social and economic institutions and decision making, is essential. Social functions address the needs of individuals and social institutions, such as government, health care, manufacturers, retail and service businesses, faith-based and nonprofit organizations, educational institutions, day care centers, finance, and news media. Much of the information may already be contained in existing planning documents.

\section{ASPECTS OF SOCIAL DIMENSIONS TO CONSIDER (ACTION 2-3)}

\section{Social functions}

$>$ What functions and services are provided by social institutions?

$>$ What dependencies exist between social institutions?

$>$ What dependencies exist between social institutions and the built environment?

$>$ Which institutions are most vulnerable to disruptions in supply chains?

$>$ Which institutions cannot be operated with temporary measures (e.g., generators) or be relocated temporarily?

\section{Economic factors}

$>$ Is the community economically diverse, or does it depend heavily on one type of business or industry?

$>$ Are key businesses or notable percentages of employees located in hazard-prone areas in the community?

$>$ Are there specific businesses and industries not currently involved with resilience planning that have a vested interest in supporting these efforts? 


\section{CHARACTERIZE THE COMMUNITY'S BUILT ENVIRONMENT}

Action 2-4: Characterize the built environment. The planning team should characterize the built environment - buildings and infrastructure systems - that community services and functions rely upon. Dependencies between buildings and infrastructure systems should also be identified.

A community's built environment is foundational to community functions, services, and the variety of daily activities of its residents. The built environment includes, but is not limited to:

- Buildings (e.g., critical, commercial, industrial, residential)

- Transportation facilities (e.g., roads, tunnels, rail, airports, maritime ports)

- Energy systems (e.g., electric power, fuel systems)

- Communication systems (e.g., internet, phone, cellular)

- Water and wastewater systems (e.g., reservoirs, pumping stations, transmission network, water treatment plants, storm water system, wastewater treatment)

Typical information collected for individual buildings and infrastructure systems includes ownership, location, current use, size, age, construction type, zoning, current condition (e.g., maintenance, retrofits, or upgrades) - along with applicable codes, standards, and regulations at the time of design. Information on current conditions and dependencies on other buildings or infrastructure systems is also necessary to understand functional connections. This information will contribute to understanding how the built environment is expected to perform if one or more of the systems, or a segment of a system, stops providing services (e.g., energy services). Infrastructure data may be collected by public agencies or departments, regional planning commissions or metropolitan planning organizations, or utilities - or they may be found in local plans (e.g., comprehensive plans, hazard mitigation plans) or GIS databases.

Some communities draw upon standing "service provider councils" or establish them as part of their resilience planning initiatives to define interdependencies among infrastructure systems and to develop compatible performance goals and solutions. Additionally, community growth may have strained infrastructure capacity and the council can provide input on future needs.

Related to risk levels, overlaying spatial hazard information with infrastructure locations using GIS-based maps can help communities understand whether their buildings or infrastructure systems are located in higher-risk areas. For instance, many communities and key installations were established before flood zones were mapped or updated; consequently, buildings and infrastructure systems may be subject to flood damage. Other communities have buildings and infrastructure systems located in liquefaction zones and may not perform well if a significant seismic event occurs.

One way to help identify and prioritize buildings and infrastructure systems is to ask for community feedback on the question: "What institutions and services are most important to you?" Institutions and services often require more than one building and can be addressed through building clusters that support functional categories oriented around types of services provided. This information can help the planning team understand how elements of the built environment work together to provide services before and after hazard events and will be used in Step 3. Further, functionality of buildings and building clusters can be used to assess the value of alternative resilience projects, instead of relying solely upon replacement value of an asset. For example:

- Health care clusters: Hospitals and acute care facilities/services are under Critical Medical. Medical provider offices are addressed under the Community Recovery functional category. Other health services, such as pharmacies, dialysis clinics, and treatment centers should also be included where they are most likely to be located.

- Business clusters: A large employer may be placed in the Housing/Neighborhoods functional category under the Critical Retail building cluster. For instance, building and infrastructure repairs may be needed for short-term recovery. Other businesses may be placed under the Housing/Neighborhoods/Businesses or Community Recovery functional categories. Banks and ATMs, gas stations, and supermarkets are examples of other facilities/services that need to be considered for placement. 
Terms To Know...

Building Clusters: The term cluster refers to a set of buildings - and supporting infrastructure systems - that serve a common function (e.g., housing, healthcare, retail).

Clusters are groups of buildings that, taken as a whole, meet the community's needs for different types of services such as health, education, government, shelter, etc. Building clusters may be collocated or have buildings distributed throughout the community.

Functional Categories: These are categories of community functions and services needed during recovery after a hazard event. The main categories include:

- Critical Facilities - Medical, Emergency Operations, Government, Non-ambulatory Facilities.

- Emergency Housing - Shelters, Residential Shelter in Place.

- Housing/ Neighborhoods - Critical Retail, Religious and Spiritual Centers, Residential Housing, K-12 Schools, Child Care, Hotels and Motels.

- Community Recovery - Manufacturing, Commodity Services, Service Professions, Conference \& Event Venues.

Additional functions and service can be identified for planning, as shown in Table 2-2 and Table 3-1 for Step 3.

Using the Guide Templates. Table 2-1 provides an example of linking social functions and services to building clusters for Critical Facilities. Template 2-1 provides a listing of information the planning team may wish to collect to complete Action 2-4. Templates 2-2 and 2-3 for the built environment - building cluster and infrastructure systems are organized by functional categories. These templates also include links to social functions and services. Other functional categories are Emergency Housing, Housing and Neighborhoods, and Community Recovery.

\section{BUILDING CLUSTERS AND FUNCTIONAL CATEGORIES (ACTION 2-4A)}

The NIST Guide identifies four building clusters by functional category and phases of recovery:

$>$ Critical Facilities (short-term recovery)

$>$ Emergency Housing (short-term recovery)

$>$ Housing/Neighborhoods (intermediate recovery)

$>$ Community Recovery (long-term recovery)

Each building cluster has general goals for time-to-recovery of functionality as indicated by the phases of recovery: short-term, intermediate, and long-term.

The short-term phase focuses on rescue, stabilization, and preparing for recovery and is expected to occur over a period of days.

The intermediate phase focuses on restoring neighborhoods, workforce, and caring for particularly impacted or otherwise vulnerable populations and extends for weeks to months.

The long-term phase relates to restoring the community's economy, social institutions and physical infrastructure and may continue for years after the initial event. 
Table 2-1. Example of linking the functional category of Critical Facilities and its Building Cluster to social functions and services (Action 2-4)

\begin{tabular}{|c|c|c|}
\hline Functional Category & Building Cluster & Functions and Service Provided \\
\hline \multirow{16}{*}{ Critical Facilities } & Critical Medical & Acute care \\
\hline & Acute Care Hospitals & Triage, emergency care \\
\hline & \multirow{4}{*}{$\begin{array}{l}\text { Emergency Operations } \\
\text { Centers }\end{array}$} & Transportation coordination \\
\hline & & 9-1-1 services, dispatch \\
\hline & & Emergency Operations \\
\hline & & Incident response coordination (e.g., utilities, public safety agencies, etc.) \\
\hline & \multirow{8}{*}{$\begin{array}{l}\text { Critical Government - First } \\
\text { Responder Facilities }\end{array}$} & Transportation, road access, debris removal \\
\hline & & Communication \\
\hline & & Internal IT System functionality \\
\hline & & Fire, emergency services \\
\hline & & Police, public safety \\
\hline & & Building safety assessment \\
\hline & & Response services documentation and records \\
\hline & & Trash, debris landfill \\
\hline & \multirow{2}{*}{$\begin{array}{l}\text { Non-ambulatory Facilities - } \\
\text { Prisons, nursing homes, etc. }\end{array}$} & Shelter, food, care, security \\
\hline & & Adult care, nursing, custodial care \\
\hline
\end{tabular}

\section{KEEPING RECORDS OF THE BUILT ENVIRONMENT (ACTION 2-4B)}

Federal reimbursements after a hazard event require data and records about disbursements related to postincident recovery, payments to subsidize housing, and other recovery costs. Maintaining records of infrastructure related information both prior to hazard events (including photos, procurement records, and contracts) can help facilitate completion of applications. Examples include:

$>$ Codes and standards adoption and enforcement.

$>$ Conditions of roadways and bridges.

$>$ Installation of plastic water distribution lines - since wildfires may cause these pipes to fail - and even melt making it difficult for the local government to prove that they were in-place.

$>$ Land and housing values - which are critical to funding following a disaster and also help local governments to analyze the market and understand needed incentives. 


\section{CONNECT COMMUNITY SOCIAL DIMENSIONS TO THE BUILT ENVIRONMENT}

Action 2-5: Link social functions to the built environment. The planning team should identify links between social functions and the buildings and infrastructure systems that support them for day-to-day operations and during a recovery process. Informed by these links, building clusters and supporting infrastructure should be defined by how they support social functions.

Once the social dimensions and built environment are characterized, social functions can be linked to their support by buildings and infrastructure systems. This requires fact-finding and coordination among planning team members and stakeholders.

Table 2-2 offers examples of links between various social institutions and transportation systems, as well as possible direct and indirect impacts of transportation system damage. The Guide provides similar tables (Guide Tables 10-6 through 10-8) for other infrastructure systems that can assist planners understanding and identifying these linkages. This action will offer fresh insights into how social functions and services depend on the built environment - and the interdependencies among those systems.

Table 2-2. Example of linking social institutions and transportation systems (Action 2-5)

\begin{tabular}{|c|c|c|c|c|}
\hline \multirow[t]{2}{*}{ Social Institution } & \multirow{2}{*}{$\begin{array}{l}\text { Purpose of Transportation } \\
\text { within each Social Institution }\end{array}$} & \multirow{2}{*}{$\begin{array}{c}\text { How Actualized } \\
\text { within Built } \\
\text { Environment }\end{array}$} & \multicolumn{2}{|c|}{$\begin{array}{c}\text { Possible Impacts if Transportation Systems } \\
\text { are Damaged }\end{array}$} \\
\hline & & & Direct & Indirect \\
\hline Family & Access to and from housing & $\begin{array}{l}\text { Roads, bridges, and } \\
\text { tunnels } \\
\text { Airports } \\
\text { Railways and stations }\end{array}$ & $\begin{array}{l}\text { Displaced population (lack } \\
\text { of access) } \\
\text { Inability to physically } \\
\text { connect with others }\end{array}$ & $\begin{array}{l}\text { Demand for } \\
\text { short-term/ nearby } \\
\text { shelter }\end{array}$ \\
\hline Economic & $\begin{array}{l}\text { Distribute goods for processing } \\
\text { Obtain labor and capital } \\
\text { Distribute intermediate goods } \\
\text { Distribute final goods for sale } \\
\text { Bring sellers (providers) and } \\
\text { consumers together } \\
\text { Getting to and from work }\end{array}$ & $\begin{array}{l}\text { Seaports } \\
\text { Pipelines } \\
\text { Public transit }\end{array}$ & $\begin{array}{l}\text { Loss of access to raw } \\
\text { materials } \\
\text { Loss of employment } \\
\text { Increase in commuting } \\
\text { time and cost } \\
\text { Consumers unable to } \\
\text { obtain goods and services }\end{array}$ & $\begin{array}{l}\text { Loss of taxes, } \\
\text { market share } \\
\text { Price increases }\end{array}$ \\
\hline
\end{tabular}

Note: The entire table should be completed by the planning team; Example in Guide Chapter 10.

Mapping and GIS capabilities can also help team members and stakeholders understand the linkages and improve communication. Other organizations in the private sector or other levels of government may be able to assist. 


\section{Q'Useful Resources}

Guide Brief 1 - Characterize the Population:

https://nvlpubs.nist.gov/nistpubs/SpecialPublications/NIST.SP.1190GB-1.pdf

Guide Brief 2 - Identify Social Institutions:

https://nvlpubs.nist.gov/nistpubs/SpecialPublications/NIST.SP.1190GB-2.pdf

Guide Brief 5 - Assessing Energy System Dependencies:

https://nvlpubs.nist.gov/nistpubs/SpecialPublications/NIST.SP.1190GB-5.pdf

Guide Brief 6 - How Communities Can Work with Communication Service Providers

to Understand Communication Systems:

https://nvlpubs.nist.gov/nistpubs/SpecialPublications/NIST.SP.1190GB-6.pdf

Guide Brief 10 - Linking Social Dimensions and Building Clusters:

https://nv/pubs.nist.gov/nistpubs/SpecialPublications/NIST.SP.1190GB-10.pdf

Guide Brief 14 - Forming a Collaborative Planning Team and Engaging the Community

https://nvlpubs.nist.gov/nistpubs/SpecialPublications/NIST.SP.1190GB-14.pdf

NISTIR 8231 - Implementation of the NIST Community Resilience Planning Guide for Buildings and Infrastructure Systems: https://nvlpubs.nist.gov/nistpubs/ir/2018/NIST.IR.8231.pdf (See pages 69-72)

Playbook tables and templates: https://www.nist.gov/el/communityresilience/community-resilience-planning-guideplaybook-templates-additional-resources 


\section{STEP 3: DETERMINE GOALS AND OBJEGTIVES}

\section{Objective}

Determine the community's resilience goals and relate them to the performance of the built environment and its ability to support the recovery of community functions after a hazard event.

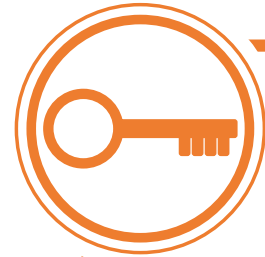

\section{Key Take-Aways}

- Community resilience plans are based on long-term growth and development goals.

- Community resilience goals need to be incorporated into other community plans to facilitate coordination and minimize conflicts and gaps between plans.

- There are two types of performance needed to assess the built environment: 1) desired performance goals for recovery of function (independent of hazard type) and 2) anticipated performance for recovery of function if an event were to occur in the near future.

\section{Actions to Accomplish}

$\square$ 3-1: Identify long-term community goals.

$\square$ 3-2: Determine desired performance goals for buildings and infrastructure systems.

$\square$ 3-3: Define community hazards and levels.

$\square$ 3-4: Determine anticipated performance of buildings and infrastructure systems to support social functions for hazard events.

$\square$ 3-5: Summarize the results. 


\section{IDENTIFY LONG-TERM COMMUNITY GOALS}

Action 3-1: Identify long-term community goals. The planning team should identify long-term community goals that will inform or be affected by community resilience plans.

Identifying community-level goals will assist in developing resilience strategies so that prioritized investments in buildings and infrastructure will also promote the community's ability to prepare for anticipated hazards, adapt to changing conditions, and withstand and recover rapidly from disruptions. In some cases, this approach might find ways to achieve community goals not previously considered but would result in greater social, economic, and resilience benefits.

Community goals may already be identified or defined in a comprehensive or general plan, land-use plan, pre-disaster recovery plan, hazard mitigation plan, and/or capital investment budget. Long-term community goals may go beyond resilience planning but will be improved by including resilience. For example:

- To attract new business investment, a community may wish to develop more resilient physical infrastructure, such as increasing redundancy or diversity in transportation options - like an additional bridge to provide a second access point for traffic to the downtown area or an industrial park.

- To increase its social well-being and equity, a community may want to develop parks that also act as basins for flood waters or it may seek to improve transportation access to underserved areas.

- A community may need to improve the performance of its water or wastewater treatment plants to minimize disruption of service and meet environmental requirements (e.g., reduce the risk of damage during hazard events).

- A community may want to diversify its economy with increased sources from a range of sectors and markets to encourage positive economic growth and development.

- A community's population growth and its projected demands on healthcare institutions may call for expanded health facilities that will also be functional immediately following a hazard event.

\section{COMMUNITY RESILIENCE GOALS}

Community resilience goals should help to integrate and align existing community plans and support long-term community goals. Each of these plans should incorporate appropriate community resilience goals, especially master, comprehensive, and mitigation plans. Additionally, the resilience goals and supporting data and templates should be documented in a separate report to provide a reference document for all community plans, and to help avoid inadvertent alterations to the resilience plan. Resilience goals should reflect and leverage the goals and information from the other plans. 
SET DESIRED PERFORMANCE GOALS FOR RESILIENCE

Action 3-2: Determine desired performance goals for buildings and infrastructure systems. The planning team should determine specified times for recovery of functions or services provided by building clusters and/or infrastructure systems, with input from owners, operators, and other key stakeholders.

Long-term community goals should inform specific community resilience goals.

The desired performance goals are expressed as recovery times and should build on the social and economic characteristics and needs of the community

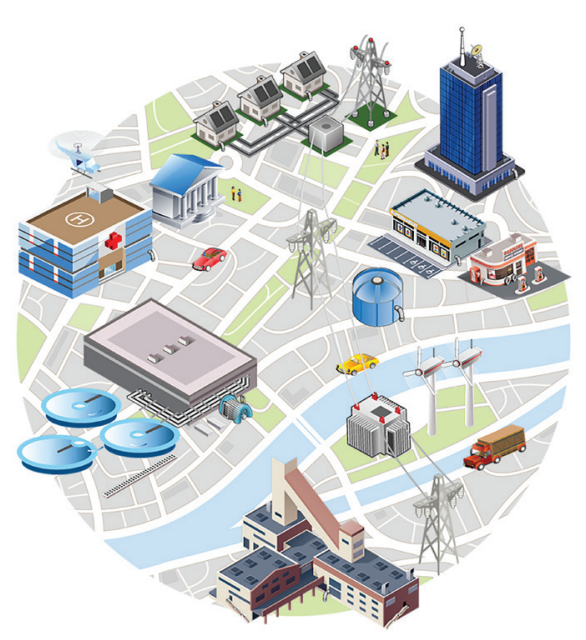
from Step 2. For example:

- The desired performance for critical facilities, such as emergency rooms and 911 call centers, is typically continuous service or minimal disruption after a hazard event.

- Most residents should be able to shelter in their homes or in emergency housing after a hazard event, and utility services should be restored in a maximum of one or two weeks to keep residents in the community.

- Small businesses and major employers need to resume within one-to-two weeks to maintain the economy; schools and daycare need to have similar goals for resuming operations so all parents can work.

- In contrast, it may be reasonable to set recovery times for non-emergency city services at weeks or months, such as parks and recreation facilities.

The desired recovery time between a hazard event and the recovery of community functions and services is independent of the type of hazard. For instance, the desired recovery time for a hospital or utility will be the same for a range of hazards (e.g., flood, hurricane, earthquake). This is because community needs are likely to be the same for recovery of functions following any hazard event; the actual performance that is anticipated for a specific hazard event (defined in Action 3-3) is evaluated separately in Action 3-4.

\section{TIME TO RECOVERY OF FUNCTION}

The Guide expresses the desired performance goals for buildings and infrastructure as the time needed to recover function.

$>$ Time-to-recovery goals for an individual facility should not be developed in isolation.

$>$ Both the facility and its supporting infrastructure affect the desired performance goal, or specified recovery time.

$>$ Recovery of functions can be met by temporary measures until the service can be provided by the intended facility and supporting infrastructure. 
The planning team should address questions that get to the heart of resilience requirements and help identify the desired performance goals (see Boulder County Resilient Design Performance Standard) for the community, such as:

- When and how much do the buildings and infrastructure systems supporting each business or institution need to recover their intended functions and services?

- What timeframe for recovery is needed for housing, schools, and businesses before the community's ability to serve its members is adversely affected?

- Where is it reasonable to use temporary measures until repairs can be completed?

These kinds of resilience questions should be a critical focus for the planning team.

\section{BOULDER COUNTY COLLABORATIVE EXAMPLE: DESIRED PERFORMANCE GOALS AND FUNCTIONAL LEVELS OF RECOVERY (ACTION 3-2A)}

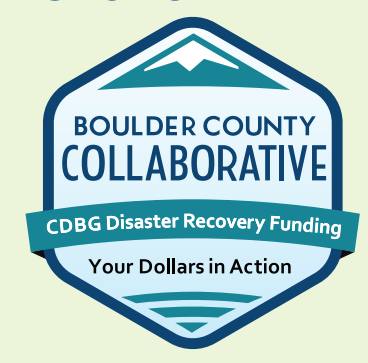

Hospitals. The performance goal for hospitals calls for county-wide capacity to provide a minimal level of service immediately after a disaster event. At least one hospital in Boulder County must be open and servicing minimal needs to support critical relief activities. Other hospitals in the county need to be functional within 4 to 8 weeks to provide routine services after the event. All hospitals in the county should be operational within 4 months of a design hazard event such that they are able to provide both normal and peak demand for services.

Housing. The performance goal for housing in Boulder County calls for all housing to provide a minimal level of housing for all county residents within 1 to 4 weeks. Performance at this level allows residents to shelter in their homes during relief efforts so that they can contribute to their own and the overall community recovery. Within 8 to 12 weeks, all housing should be functional. Within two years of a hazard event, virtually all housing must be operational so that it can withstand design-level hazard events.

Businesses - Manufacturing. The performance goal for manufacturing calls for a minimal level of manufacturing to resume within 1 to 4 weeks. Within 4 to 8 weeks most manufacturing capacity in Boulder County should be functional and able to conduct routine operations. Virtually all manufacturing should be operational within 8 to 12 weeks and capable of normal and peak demand operations.

Conference and Event Venues. These venues should be available at a minimal level within 8 to 12 weeks so that community meetings can be held in safe locations during relief. Within 4 months, conference and event venues should be functional for routine and nonexceptional operations during recovery. Within 4 to 24 months, all conference and event venues should be operational with the capacity to handle both normal and peak demand. (It was decided that there were few alternate locations for businesses and manufacturing, so operational levels of recovery were needed within 8 to 12 weeks. The housing stock was large, and there were alternative options available. This led to a goal of up to two years for operational levels of recovery for a more resilient housing stock.)

Each community is different. For example, a performing arts center might not be critical in one mid-sized city; for a smaller community where the center attracts tourists and is a primary supporter of downtown businesses, a shorter recovery time may be strongly desired. For other communities, a manufacturing plant that is crucial to the country's military supplies may be determined to be much more critical than another type of factory. Guide Brief 9 and Guide Brief 11 offer additional guidance for determining desired performance goals. 
Design professionals are expected to follow relevant standards, codes, and best practices when designing and constructing buildings and infrastructure systems. However, current practice is developed for individual projects, and does not spell out the means or the criteria by which to consider their integrated performance at the community level. The community perspective is provided by setting desired performance goals for building clusters and interdependencies based on community needs. This is a core value provided by community resilience planning.

\section{MORE ON DESIRED “TIME-TO-RECOVERY” GOALS - BOULDER COUNTY COLLABORATIVE EXAMPLE (ACTION 3-2B)}

In Boulder County's Resilient Design Performance Standard, "time-to-recovery goals are set to indicate the acceptable time allowed to restore community services after a disaster. The goal applies to all the buildings or infrastructure elements in the cluster of similar-functioning facilities, not to the condition of any single building or infrastructure system.

This approach helps communities to gauge how robust any individual element within a cluster must be to meet the time-to-recovery goals. If the cluster as a whole can meet the time-to-recovery performance goal, then the need for any one element within that cluster to meet that goal is not as crucial. Conversely, if the cluster as a whole cannot meet the time-to-recovery goal, then any specific project within that cluster is an opportunity to improve the overall capacity of the cluster to achieve that goal.

Over time as more and more projects are built or rebuilt, the resilience of the community will improve as more and more of each cluster increases its capacity to meet the time-to-recovery goal."

Phases of Recovery. Recovery times for building clusters and infrastructure systems are organized around sequential recovery phases. The Guide uses the recovery phases defined in the National Disaster Recovery Framework: short-term, intermediate, and long-term (Figure 3-1).

The first phase (short-term) usually focuses on rescue, stabilization, and preparing for recovery, and is expected to occur over a period of days. The second phase (intermediate) focuses on restoring neighborhoods, workforce, and caring for vulnerable populations and extends for weeks to months. The third phase (long-term) relates to restoring the community's economy, social institutions and physical infrastructure, and may continue for years after the event. Activities during each recovery phase may overlap in planning and execution.

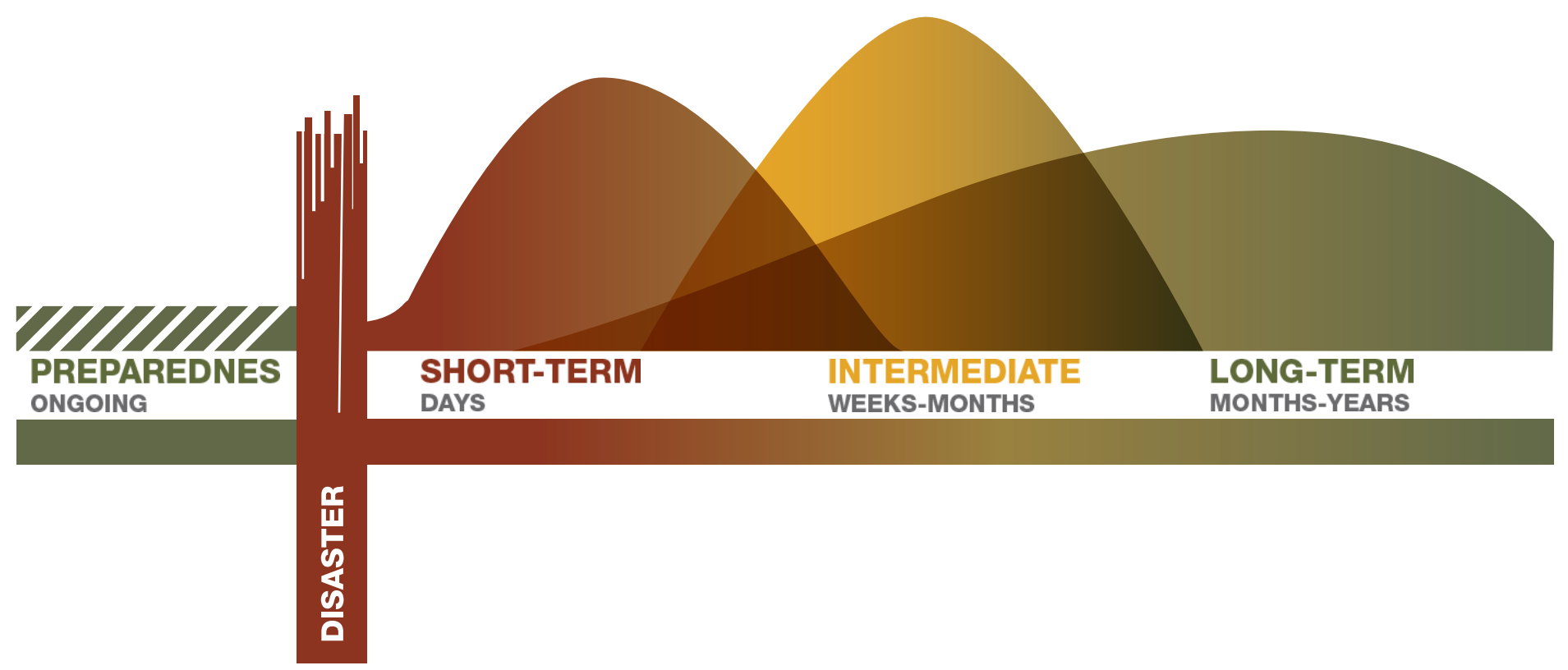

Figure 3-1: National Disaster Recovery Framework recovery continuum 
Communities should consider human and social needs when assigning building clusters to the three recovery phases. Table 3-1 gives an example of building clusters listed for functional categories and recovery phases. Infrastructure systems that support the clusters are not listed but also should be considered.

While three recovery phases are designated, there will be considerable overlap in their initiation and completion, as indicated in Figure 3-1.

Functional Levels for Building Clusters. The Guide recommends using three functional levels for specifying the desired time-to-recovery performance goal for building clusters. The percentages may vary, but generally meet the following levels of recovery:

- Minimal: $30 \%$ of building cluster is functional - minimum number of facilities needed to initiate the minimum functions and services required of a building cluster

- Functional: $60 \%$ of building cluster is functional - minimum number of facilities to meet the usual operations (functions and services) of a building cluster

- Operational: $90 \%$ of building cluster is functional - minimum number of facilities needed to declare that the building cluster is operating at normal capacity

Setting functional levels helps define how a building cluster will meet the desired performance goal while addressing immediate response needs following a hazard event.

Table 3-1 provides an example of the supporting materials in Template 3-1 to specify desired performance goals and functional levels for the phases of recovery for building clusters. Template 3-2 is used to document desired performance goals for infrastructure systems. Anticipated performance is addressed in Action 3-4 and Table 3-3. More examples of performance tables are found in Guide Tables 9-11 to 9-31. 
Table 3-1. Example Building Cluster Table: Desired Performance Goals (Action 3-2)

\begin{tabular}{|c|c|c|c|c|c|c|c|c|c|}
\hline \multirow{4}{*}{ Building Clusters } & \multicolumn{9}{|c|}{ Design Hazard Performance } \\
\hline & \multicolumn{3}{|c|}{ Phase 1: Short-Term } & \multicolumn{3}{|c|}{ Phase 2: Intermediate } & \multicolumn{3}{|c|}{ Phase 3: Long-Term } \\
\hline & \multicolumn{3}{|c|}{ Days } & \multicolumn{3}{|c|}{ Weeks } & \multicolumn{3}{|c|}{ Months } \\
\hline & $\mathbf{0}$ & 1 & $1-3$ & $1-4$ & 4-8 & 8-12 & 4 & $4-24$ & $24+$ \\
\hline \multicolumn{10}{|l|}{ Critical Facilities } \\
\hline Emergency Operation Centers & $90 \%$ & & & & & & & & \\
\hline First Responder Facilities & $90 \%$ & & & & & & & & \\
\hline Hospitals & $90 \%$ & & & & & & & & \\
\hline $\begin{array}{l}\text { Buildings with Non-ambulatory Occupants } \\
\text { (prisons, nursing homes, etc.) }\end{array}$ & $90 \%$ & & & & & & & & \\
\hline Critical Factory & $90 \%$ & & & & & & & & \\
\hline \multicolumn{10}{|l|}{ Emergency Housing } \\
\hline Temporary Emergency Shelters & $30 \%$ & $90 \%$ & & & & & & & \\
\hline $\begin{array}{l}\text { Single and Multi-family Housing } \\
\text { (shelter in place) }\end{array}$ & $60 \%$ & & & $90 \%$ & & & & & \\
\hline \multicolumn{10}{|l|}{ Housing/Neighborhoods } \\
\hline Critical Retail & & $30 \%$ & $60 \%$ & $90 \%$ & & & & & \\
\hline Religious and Spiritual Centers & & & $30 \%$ & $60 \%$ & $90 \%$ & & & & \\
\hline Single and Multi-family Housing (Full Function) & & & $30 \%$ & & $60 \%$ & & $90 \%$ & & \\
\hline Schools & & & $30 \%$ & $60 \%$ & $90 \%$ & & & & \\
\hline Hotels \& Motels & & & $30 \%$ & & $60 \%$ & $90 \%$ & & & \\
\hline \multicolumn{10}{|l|}{ Community Recovery } \\
\hline Businesses - Non-critical Factory & & & & $30 \%$ & $60 \%$ & $90 \%$ & & & \\
\hline Businesses - Commodity Services & & & & $30 \%$ & $60 \%$ & & $90 \%$ & & \\
\hline Businesses - Service Professions & & & & $30 \%$ & & $60 \%$ & & $90 \%$ & \\
\hline Conference and Event Venues & & & & $30 \%$ & & $60 \%$ & & $90 \%$ & \\
\hline
\end{tabular}

\begin{tabular}{|l|l|c|l|l|}
\hline \multicolumn{2}{|c|}{ Disturbance } & \multicolumn{2}{c|}{ Restoration Levels } \\
\hline Hazard Type & Flood & $30 \%$ & Minimal \\
\hline Hazard Level & Design & $60 \%$ & Functional \\
\hline Affected Area & Community & $90 \%$ & Operational \\
\hline Disruption Level & Moderate & X & Anticipated Performance \\
\hline
\end{tabular}




\section{DEFINE COMMUNITY HAZARDS AND LEVELS}

Action 3-3: Define community hazards and levels. The planning team should identify the prevailing hazards that will affect community functions and resilience.

A better understanding of a community's performance in terms of hazards and levels can be found by using three levels for each prevailing hazard:

- Routine events are more frequent but should cause minimal damage and no loss of community functions.

- Design events are used to design the built environment; design loads are specified in building codes. For many hazards, where the built environment meets current code requirements, there should be minimal damage or loss of community functions.

- Extreme events may also be defined in building codes for some hazards; they are the most likely to cause extensive damage. Extreme events are evaluated to determine if critical functions will be available after a hazard event.

A community resilience plan should be anchored around the design hazard level.

The routine and extreme hazard levels are evaluated to ensure that the community is planning for a range of possibilities. At the routine level, buildings and infrastructure systems should not experience any significant damage that would disrupt social functions in the community.

At the extreme level, critical facilities and infrastructure systems should remain partially functional and able to support the response and recovery of the community as defined by the performance levels. Other buildings and infrastructure systems should perform at a level that protects the occupants, though they may need to be rescued. Emergency response plans should be developed for scenarios based on this hazard level. For many hazards such as flood, wind, earthquakes, and snow, design events are specified in codes and standards for the built environment.

This information helps a community to understand how the built environment will perform and recover over a range of hazard types and levels. The Guide lists three levels for hazards addressed in building codes and standards for natural hazards in Guide Table 4-4.

When codes don't define design hazard levels (e.g., wildfires or tornadoes), the community can turn to available guidance by professional organizations (e.g., the US Forest Service for wildfires, FEMA and ASCE for tornadoes).

Historical data may be useful for understanding hazards and consequences but need to be interpreted and used carefully for future projections. For example, many communities have experienced multiple flooding events in various locations, but these events may not meet or exceed the 100-yr or 500-yr flood events defined by FEMA. Flooding may also occur in other locations if stormwater systems are overwhelmed or sea level rise contributes to flood elevations.

Many communities already have identified prevailing hazards - and their history, design-level severity, and probability of occurring. As part of developing a hazard mitigation plan, planners conduct a risk assessment which includes identifying all hazards affecting the planning area. This information appears in their plans for FEMA Hazard Mitigation requirements, emergency operations, or continuity of operations. Table 3-2 lists the types of hazards that may have a significant impact on a community. Further information on hazards is available in the Guide Section 4.1.3. Template 3-3 helps document community hazards and their event levels. 
TABLE 3-2. POTENTIAL COMMUNITY HAZARDS (ACTION 3-3)

$\begin{array}{llll}>\text { Avalanche } & >\text { Human-caused } & >\text { Storm surge } & >\text { Volcanic eruption } \\ >\text { Blizzard } & >\text { Hurricane } & >\text { Technological } & >\text { Wildfire } \\ >\text { Drought } & >\text { Landslide } & >\text { Tornado } & >\text { Windstorm } \\ >\text { Earthquake } & >\text { Liquefaction } & >\text { Tsunami } & \end{array}$

Hazard occurrence vs impact. The occurrence of a hazard type and magnitude does not imply a level of impact, such as damage and losses. The level of preparedness and resilience of a community can result in very different outcomes.

Hazard impact is a result of the consequences of a given hazard event. Two measures are used in the Guide to indicate the anticipated consequences:

- Affected area may be a portion of a community (local), most or all of the community (community), or across the community and surrounding communities (regional).

- Level of disruption to community functions may be handled within normal operations (minor), require activation of community/state emergency response assistance (moderate), or require activation of federal emergency response assistance (severe).

Hazard impacts are identified in Table 3-1 in the sub-table labeled Disturbance which lists the hazard and anticipated impact levels.

\section{DETERMINE ANTICIPATED PERFORMANCE}

Action 3-4: Determine the anticipated performance of buildings and infrastructure systems. For each hazard event of interest, the planning team should determine the time to recovery of community functions, accounting for dependencies and varying rates of recovery.

This action considers how the community's current building clusters and infrastructure systems would fare in a potential hazard event that occurs in the near future. The estimate of performance, based on the current condition of the built environment as characterized in Step 2, is referred to as the anticipated performance. The question being addressed is: how long will it take to recover community functions for a hazard event given the current state of the built environment and the estimated level of damage and loss? The anticipated recovery times are then compared to the desired performance goals, also expressed as recovery times.

A-Z Terms To Know...

- Anticipated performance: The expected time for recovery of functions or services by an existing building and/or infrastructure system if a hazard event occurred in the near future. 
Most buildings and infrastructure systems in service today were designed to serve their intended functions on a daily basis under normal environmental conditions and routine hazard events. In addition, buildings and other structures are designed to provide occupant safety during a design hazard event, but they may not continue to be functional.

Lack of experience with a damaging hazard event, and lack of understanding about the level of damage to be expected when a significant hazard event occurs, can lead to misconceptions about a community's vulnerability. Communities can gain better insights into their vulnerabilities based on national experience, not just local events, and can better address those vulnerabilities by adopting and enforcing land use guidelines and national model building codes. The cost of compliance for new construction is often minimal compared to the cost of recovery and reconstruction.

\section{VULNERABILITY - CONSIDER INTERNAL SYSTEMS AND SERVICES (ACTION 3-4A)}

After a hazard event - and when thinking about the resilience of the built environment as part of a planning process - vulnerabilities internal to buildings or systems are often overlooked, as owners focus on the structure's integrity or the availability of external utilities.

For instance, following a flood, the structure may appear to be sound, but internal power and communication systems may be damaged that are vital for reliable operations. During assessments of anticipated performance, consider those internal systems, too.

There are multiple options for determining anticipated performance:

- Expert Judgement: Estimate anticipated performance using expert judgment of the team, stakeholders, and other experts as needed.

- Past Hazard Experience: Estimate anticipated performance using data from past hazard events similar to the hazard event being analyzed, taking into account changes to codes and new construction that have occurred in the interim.

- System-Level Assessment: Use performance assessments previously conducted for buildings or infrastructure systems.

- Building or Community-Level Assessment: Commission technical experts to assess anticipated performance using available technical tools. The HAZUS modeling tool, for example, is commonly used to assess the impact of earthquake, flooding, hurricane (wind and storm surge), and tsunami events on buildings at a community scale.

Current engineering practice for predicting the performance of buildings and infrastructure systems under specific hazard events often is based on expert judgment or the past experience of other communities. For more detail, Guide Chapters 12 through 16 provide considerations for estimating the performance of existing buildings and infrastructure systems. Guide Brief 4 and Guide Brief 4A offer additional guidance on determining anticipated performance of the built environment.

Using the Guide Templates. The anticipated performance - time to operational recovery levels - needs to be determined for buildings clusters and infrastructure systems and documented in Template 3-1 and Template 3-2 with the desired performance goals. It is important to include interdependencies between buildings and infrastructure systems when determining anticipated, or expected, recovery levels. For example, an educational building cluster all K-12 schools, administrative buildings, bus facilities, and maintenance facilities - requires buildings, power, water and wastewater, and communications to be functional, and transportation routes for staff and students to reach the facilities.

As another example, Table 3-3 has added the anticipated performance for the building clusters to the desired performance goals in Table 3-1. Additional templates should also be filled out for the infrastructure systems and 
coordinated with other templates as appropriate. The anticipated performance tables also can be used to compare the effects of alternative solutions for improving community resilience or to track changes in anticipated performance over time.

Table 3-3. Example Building Cluster Table: Desired Performance Goals and Anticipated Performance (Action 3-4)

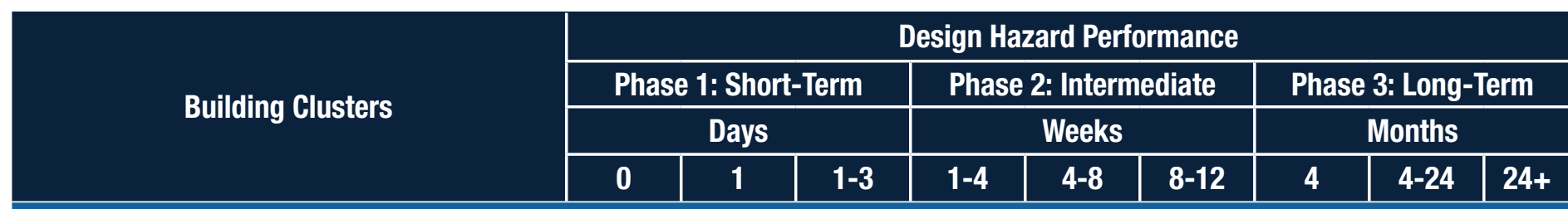

Critical Facilities

\begin{tabular}{|c|c|c|c|c|c|c|c|c|c|}
\hline Emergency Operation Centers & $90 \%$ & & & & & & & $X$ & \\
\hline First Responder Facilities & $90 \%$ & & & & & & & $X$ & \\
\hline Memorial Hospital & $90 \%$ & & & & & & & $x$ & \\
\hline $\begin{array}{l}\text { Non-ambulatory Occupants (prisons, nursing } \\
\text { homes, etc.) }\end{array}$ & $90 \%$ & & & & & & & $x$ & \\
\hline Critical Factory & $90 \%$ & & & & & & & $x$ & \\
\hline \multicolumn{10}{|l|}{ Emergency Housing } \\
\hline Temporary Emergency Shelters & $30 \%$ & $90 \%$ & & & & & & & $X$ \\
\hline $\begin{array}{l}\text { Single and Multi-family Housing (shelter in } \\
\text { place) }\end{array}$ & $60 \%$ & & & $90 \%$ & & & & & $x$ \\
\hline \multicolumn{10}{|l|}{ Housing/Neighborhoods } \\
\hline Critical Retail & & $30 \%$ & $60 \%$ & $90 \%$ & & & & & $x$ \\
\hline Religious and Spiritual Centers & & & $30 \%$ & $60 \%$ & $90 \%$ & & & & $X$ \\
\hline Single and Multi-family Housing (full Function) & & & $30 \%$ & & $60 \%$ & & $90 \%$ & & $X$ \\
\hline Schools & & & $30 \%$ & $60 \%$ & $90 \%$ & & & & $x$ \\
\hline Hotels \& Motels & & & $30 \%$ & & $60 \%$ & $90 \%$ & & & $x$ \\
\hline \multicolumn{10}{|l|}{ Community Recovery } \\
\hline Businesses - Non-critical Factories & & & & $30 \%$ & $60 \%$ & $90 \%$ & & & $x$ \\
\hline Businesses - Commodity Services & & & & $30 \%$ & $60 \%$ & & $90 \%$ & & $x$ \\
\hline Businesses - Professional Services & & & & $30 \%$ & & $60 \%$ & & $90 \%$ & $X$ \\
\hline Conference \& Event Venues & & & & $30 \%$ & & $60 \%$ & & $90 \%$ & $X$ \\
\hline
\end{tabular}

\begin{tabular}{|l|l||c|l|}
\hline \multicolumn{2}{|c|}{ Disturbance } & \multicolumn{3}{c|}{ Cluster Recovery Levels } \\
\hline Hazard Type & Flood & $30 \%$ & Minimal \\
\hline Hazard Level & Design & $60 \%$ & Functional \\
\hline Affected Area & Community & $90 \%$ & Operational \\
\hline Disruption Level & Moderate & $X$ & Anticipated Performance \\
\hline
\end{tabular}




\section{THE HIP BONE IS CONNECTED TO THE... OR CONSIDER INTERDEPENDENCIES (ACTION 3-4B)}

The functionality of structures from which key services - like healthcare, education, and housing - are delivered depends heavily on support from physical infrastructure systems. Such interdependencies needs to be considered as the team sets priorities.

For example, a hospital building is of limited value if the energy or water infrastructure is out of service. A hospital that needs to operate continuously through and after a hazard event should have temporary measures in place, such as standby generators, fuel, and water supplies for at least 96 hours. The need for temporary measures should be informed by when the power supply and potable water system are expected to be restored.

\section{SUMMARIZE THE RESULTS}

Action 3-5: Summarize the results. The planning team should document the desired performance goals and anticipated performance of existing buildings and infrastructure systems by integrating the results from individual performance tables for building clusters and infrastructure systems. This is accomplished by filling out the summary table for high-level comparisons of buildings and infrastructure system gaps in performance (Table 3-4).

The differences between the desired performance goals and anticipated performance provides a basis for evaluating and prioritizing performance gaps. Significant gaps between desired and anticipated performance can guide the development of solutions and strategies to meet long-term community goals and to improve community resilience in Step 4. Table 3-4 illustrates the summary table of gaps between desired performance goals (in yellow, orange, and green) and anticipated performance (in blue) for a design flood hazard event. Template 3-4 is a blank version of Table 3-4 that can be used by the Planning Team to complete this action.

The planning team can use the performance tables to improve communication among stakeholders and to support a comprehensive, high-level summary of the integrated performance of a community's buildings and infrastructure systems. The largest gaps between desired and anticipated performance can be used to help prioritize resilience strategies to improve the overall performance of the built environment and supported social functions.

The Guide (Chapter 9) has an example based on a fictitious community that demonstrates the six-step process and how to complete the resilience tables. Example tables are also included in Guide Chapters 12 to 16.

\section{Q'Useful NIST Resources}

Guide Brief 4 - Determining Anticipated Performance:

https://nvlpubs.nist.gov/nistpubs/SpecialPublications/NIST.SP.1190GB-4.pdf

Guide Brief 4A - Example for Determining Anticipated Performance:

https://nvlpubs.nist.gov/nistpubs/SpecialPublications/NIST.SP.1190GB-4A.pdf

Guide Brief 9 - Summarizing Resilience Goals using Performance Goals Tables:

https://nvlpubs.nist.gov/nistpubs/SpecialPublications/NIST.SP.1190GB-9.pdf

Guide Brief 11 - Determining Building Cluster Performance Goals:

https://nvlpubs.nist.gov/nistpubs/SpecialPublications/NIST.SP.1190GB-11.pdf

Playbook tables and templates:

https://www.nist.gov/el/communityresilience/community-resilience-planning-guide-playbook-templates-additional-resources 
Table 3-4: Example Summary of Goals and Anticipated Performance (Action 3-5)

\begin{tabular}{|c|c|c|c|c|c|c|c|c|c|}
\hline \multirow{4}{*}{ Summary Resilience Table } & \multicolumn{9}{|c|}{ Design Hazard Performance } \\
\hline & \multicolumn{3}{|c|}{ Phase 1: Short-Term } & \multicolumn{3}{|c|}{ Phase 2: Intermediate } & \multicolumn{3}{|c|}{ Phase 3: Long-Term } \\
\hline & \multicolumn{3}{|c|}{ Days } & \multicolumn{3}{|c|}{ Weeks } & \multicolumn{3}{|c|}{ Months } \\
\hline & 0 & 1 & $1-3$ & $1-4$ & $4-8$ & 8-12 & 4 & $4-24$ & $24+$ \\
\hline
\end{tabular}

Critical Facilities

\begin{tabular}{|c|c|c|c|c|c|c|c|c|c|}
\hline Buildings & $90 \%$ & & & & & & & $x$ & \\
\hline Transportation & & $90 \%$ & $x$ & & & & & & \\
\hline Energy & & $90 \%$ & $X$ & & & & & & \\
\hline Water & & & $90 \%$ & & $x$ & & & & \\
\hline Wastewater & & & & $90 \%$ & & & & $X$ & \\
\hline Communication & $90 \%$ & & & $x$ & & & & & \\
\hline \multicolumn{10}{|c|}{ Emergency Housing } \\
\hline Buildings & & & & $90 \%$ & & & & & $x$ \\
\hline Transportation & & & $90 \%$ & $x$ & & & & & \\
\hline Energy & & & $90 \%$ & $x$ & & & & & \\
\hline Water & & & $90 \%$ & & $x$ & & & & \\
\hline Wastewater & & & & $90 \%$ & & & & $x$ & \\
\hline Communication & & & & $90 \%$ & $x$ & & & & \\
\hline \multicolumn{10}{|c|}{ Housing/Neighborhoods } \\
\hline Buildings & & & & & & $90 \%$ & & & $x$ \\
\hline Transportation & & & $90 \%$ & $x$ & & & & & \\
\hline Energy & & & $90 \%$ & $x$ & & & & & \\
\hline Water & & & & $90 \%$ & & & & $X$ & \\
\hline Wastewater & & & & & $90 \%$ & & & $x$ & \\
\hline Communication & & & & $90 \%$ & & & $X$ & & \\
\hline \multicolumn{10}{|c|}{ Community Recovery } \\
\hline Buildings & & & & & & & & $90 \%$ & $x$ \\
\hline Transportation & & & & $90 \%$ & $x$ & & & & \\
\hline Energy & & & $90 \%$ & $x$ & & & & & \\
\hline Water & & & & $90 \%$ & & & & $x$ & \\
\hline Wastewater & & & & & & & $90 \%$ & $x$ & \\
\hline Communication & & & & $90 \%$ & & & $X$ & & \\
\hline
\end{tabular}

\begin{tabular}{|l|l||c|l|}
\hline \multicolumn{2}{|c|}{ Disturbance } & \multicolumn{3}{c|}{ Cluster Recovery Levels } \\
\hline Hazard Type & Flood & $30 \%$ & Minimal \\
\hline Hazard Level & Design & $60 \%$ & Functional \\
\hline Affected Area & Community & $90 \%$ & Operational \\
\hline Disruption Level & Moderate & $X$ & Anticipated Performance \\
\hline
\end{tabular}




\section{SIEP 4: PLAN DEVELOPMENI PRIORITIZE GAPS. . . AND FIND SOLUTIONS}

\section{Objective}

Evaluate the gaps in desired and anticipated performance of the built environment, identify administrative and construction solutions, and set priorities for addressing critical gaps based on the community's resilience goals.

\section{Key Take-Aways}

- Gaps between desired and anticipated performance of the built environment should be prioritized according to the community's resilience goals.

- Performance gaps can be addressed by administrative and construction solutions.

- Resilience solutions and strategies should identify opportunities to rapidly restore functionality and to improve community resilience.

\section{Actions to Accomplish}

4-1: Evaluate the gaps between the desired and anticipated performance of the built environment and summarize the gap evaluation.

$\square$ 4-2: Identify solutions to address gaps including both administrative and construction options.

4-3: Prioritize solutions and develop an implementation strategy. 


\section{EVALUATE GAPS BETWEEN DESIRED AND ANTICIPATED PERFORMANCE}

\section{Action 4-1: Evaluate the gaps between the desired performance goals and anticipated}

performance of the built environment and summarize the gap evaluation. The planning team should identify and prioritize performance gaps for the built environment and its impact on community functions and services.

Based on the information gathered and developed in Steps 1 to 3, the gaps between desired and anticipated performance can be identified, including contributing factors and impacts or consequences for the community. The gaps should be prioritized in terms of their importance in advancing the community's resilience goals.

The planning team should also determine if performance gaps are addressed by ongoing or planned projects. For example, plans to improve the stormwater system may not be as important to a community's overall resilience as a need for a second road or bridge to provide redundancy for emergency access or community evacuation during flood or fire events. Consideration of the impacts and consequences of these projects toward community resilience goals while taking available resources into account - will help inform the decision process.

Community resilience priorities need to be considered alongside many competing needs and interests. If all key stakeholders and current community plans are engaged in the resilience planning process, the range of interests should be part of the evaluation. Additional considerations for prioritizing performance gaps and solutions are found in Guide Brief 13.

\section{IDENTIFY POTENTIAL SOLUTIONS}

\section{Action 4-2: Identify solutions to address gaps including both administrative and construction options. The planning team should identify potential solutions to address gaps using both administrative and construction solutions.}

As the planning team has been specifying performance goals and estimating anticipated performance, the team likely has been identifying possible solutions to maintain or quickly restore community functions and services. Community resilience strategies often rely on a combination of administrative and construction solutions that are implemented over the short, intermediate, and long term. In addition to solutions generated during the planning process, other candidate solutions should be solicited from stakeholders. The community focus of the Guide can provide needed context to individual project solutions proposed to community decision makers.

\section{Administrative Solutions}

A community may begin to address performance gaps by considering administrative solutions. Administrative policies and actions can be employed to improve the quality of new construction, provide incentives for retrofit and mitigation projects, and improve permitting and other administrative factors that impact recovery time after a hazard event.

Administrative actions tend to carry lower implementation costs compared to construction solutions and can yield significant long-term benefit, though they may require policy or legislative approval. All communities, large and small, can identify and consider implementing these kinds of solutions to support their needs. Alternative land use and redevelopment strategies, for example, may be a key part of improving resilience for many communities. As an example, they often are relied upon in flood-prone hazard areas. Administrative solutions can be temporary or permanent. Mutual aid agreements established in advance can speed up the recovery process so that key parts of the infrastructure can be restored more readily. 
Communities can also adopt and enforce codes and standards with local amendments that strengthen resilience or develop mutual aid agreements that support streamlines recovery processes.

The potential administrative solutions (see the textbox for Action 4-2a) are not intended to be comprehensive, nor prescriptive, and are not listed in any particular order. Communities may have other administrative solutions that support their resilience goals and strategies. Some solutions may improve the efficiency and effectiveness of developing a plan, for example, rather than addressing specific resilience needs or options.

\section{Construction Solutions}

Targeted construction projects can greatly enhance the built environment's contribution to overall community resilience and add redundancy or robustness to buildings and infrastructure systems. Construction solutions may be the only option for addressing some of the resilience challenges the planning team identifies and prioritizes. That may include new projects and mitigation projects (e.g., barriers, relocation, improvements, renovations).

New projects can be tailored to meet the community resilience goals for immediate and long-term needs. Mitigation projects can help reduce damage from hazard events and support long-term resilience strategies. Both new and mitigation projects can also reduce demands during recovery and speed the overall recovery process.

Construction solutions usually require capital improvement budget authority and may take considerable time to complete the approval process. However, planned construction projects with resilience benefits often produce a list of "shovel ready" projects that better position the community for funding opportunities by private sources or federal agencies. This can include short-term or temporary solutions, such as modular or manufactured housing, to meet immediate needs as well as longer-term projects, such as new or relocated developments, to improve community resilience.

Importantly, after a hazard event, construction solutions should be informed by the community resilience plan and its goals for performance of buildings and infrastructure systems. This may include reducing or removing the hazard (e.g., increasing elevation, relocation for flood events) and supporting infrastructure requirements (e.g., new utilities for relocated development). Regardless of the approach taken, the key is to be thoughtful, innovative, inclusive, and open-minded about creating the right mix of affordable solutions that will match community priorities and available resources.

The potential construction solutions (see the textbox for Action 4-2b) may require long-term planning and capital investment. Each community has differing capacities for capital investment. Furthermore, each community will need to consider the costs and benefits to the public and private sectors as discussed in Action 4-3. 
1. Organize and maintain a resilience office with designated leadership. Whether full- or parttime, this office is typically assigned responsibility for leading development, implementation, and evaluation of community resilience strategies, including integration with other community plans, public outreach, collaboration with private stakeholders, and updating the plan on a regular basis.

2. Align and integrate the resilience plan with other community plans (e.g., General or Comprehensive, Pre-Disaster Recovery, Hazard Mitigation, Business Continuity Management, Land Use, Infrastructure and Transportation, Housing, Economic Development, Energy, Environmental, Climate Adaptation, and Sustainability plans). This can be a lengthy collaborative process with the responsible agencies or partners and may require community engagement - but it may determine success or failure of a community resilience plan.

3. Align the resilience plan with the community's Hazard Mitigation Plan and applications for mitigation grants.

4. Utilize land use planning tools to manage the green infrastructure (natural capital) that supports community goals and to inform design standards for construction in high hazard zones, such as floodplains, coastal areas, areas susceptible to liquefaction, etc.

5. Develop processes and guidelines for post-event assessments and repairs that will accelerate the evaluation process and the designation of buildings that can be used during repair.

6. Collaborate with adjacent communities to promote common understanding and opportunities for mutual aid during response and recovery phases. Develop mutual aid agreements as directed by the resilience plan.

7. Inform all stakeholders in transparent and publicly available methods, including announcements of resilience planning progress and results.

8. Collaborate with managers of state and federally owned and leased properties to meet regulations or codes, and to determine if the building system will function after an event.

9. Conduct education and awareness programs for all stakeholders in the community to increase understanding, preparedness, and opportunities for improving community resilience. Be mindful of the need to offer information in all languages used by community members and to be sure to reach out to underserved populations.

10. Form a service provider council of public and private infrastructure owners and provide a quarterly forum for them to discuss current activities and issues, dependencies, and future plans.

11. Provide preparedness training to the community, especially for those at higher risk of being impacted. Use social media and preparedness events and conduct awareness and training campaigns, such as the National Weather Service's Weather-Ready Nation activities. 
POTENTIAL CONSTRUCTION SOLUTIONS

(ACTION 4-2B)

\section{EXISTING CONSTRUCTION}

1. Identify opportunities for natural resource protection and preservation. This may include sediment and erosion control, stream corridor restoration, forest management, conservation easements, and wetland restoration and preservation.

2. Retrofit public buildings to initiate the resilience process in the community. This, along with relocating, or reconstructing public facilities may immediately improve the community's ability to recover from a hazard event and spur private building owners to do the same.

\section{Develop incentives and financial support} to encourage critical buildings to be retrofitted or relocated to meet community codes and regulations, and to achieve desired performance and community resilience goals.

4. Implement or augment inspection programs to identify buildings and infrastructure systems that need improvements to adequately protect life safety for the prevalent hazards.

5. Consider the appropriateness of limited mandatory relocation or retrofitting programs for critical facilities through local ordinances. Identify and communicate viable funding opportunities.

\section{NEW CONSTRUCTION}

1. Adopt and enforce the latest national model building codes, standards, and regulations for the built environment, and add requirements as needed to support specific community resilience goals.

2. Ensure enforcement of current codes and standards during permit evaluation and construction inspections.

3. Enhance codes and standards with local ordinances to support resilience plans, stating performance goals in a transparent manner.

\section{PRIORITIZE SOLUTIONS, CRAFT A} STRATEGY

\section{Action 4-3: Prioritize solutions and develop an implementation strategy. The planning team should prioritize solutions and develop a comprehensive implementation strategy that addresses the response phases and community resilience goals.}

The implementation strategy developed in this action should align with community goals, address prioritized gaps and needs, and complement other community plans. Ideally, resilience solutions and strategies should identify opportunities to rapidly restore community functions and services, and to improve the resilience of the built environment.

The best time for implementing strategies is prior to hazard events, but implementation opportunities may occur after hazard events. When the community is recovering from hazard impacts, there is significant pressure to quickly restore the built environment. Without preestablished strategies and solutions, communities often default to targeting recovery to pre-event conditions, potentially setting the community up for the same performance and wasted resources.

With advance planning, construction and administrative approaches can promote a culture that seeks community resilience. Then, if a major hazard event occurs, the groundwork is laid for community support for approved resilience strategies, such as updating codes and standards, land use changes, or retrofits to achieve desired performance goals. 


\section{ECONOMIC ANALYSIS CAN ASSIST IN MAKING CHOICES (ACTION 4-3)}

Community planners can use a benefit-cost analysis (BCA) to determine whether a project makes economic sense in terms of costs and benefits. BCA can also help frame the economic decision process by identifying and comparing resilience-related benefits and costs of competing alternatives relative to the status quo (do-nothing option).

Specifically, a community needs to determine whether investing in a project will ultimately deliver a positive return on that investment. For resilience, benefits can include direct and indirect benefits; costs can include the cost of building, operating, maintaining and retiring the project. Direct and indirect benefits, co-benefits, and losses avoided include:

$>$ Direct benefits: Conventional mitigation project benefits, such as reduction in potential losses should a hazard event occur.

$>$ Indirect benefits: Improved functionality of an infrastructure project not directly associated with its hazard performance (e.g., non-disaster related benefits).

> Direct loss: Damage and associated repair costs to restore community functions (e.g. health care) and address environmental impacts (e.g., contamination).

$>$ Indirect losses: Interruption to community business operations.

$>$ NIST's "Economic Decision Guide Software" (EDGe\$) Online Tool offers an economic decision support tool for selecting cost-effective community resilience projects. The EDGe\$ Tool can be applied across a wide range of community and project types. It helps identify and compare the present and future resilience costs and benefits associated with new capital investment versus maintaining a community's status-quo. Benefits include cost savings and damage loss avoidance because enhancing resilience on a community scale creates value, including co-benefits, even if a hazard event does not strike.

$>$ FEMA's Benefit-Cost Analysis method and toolkit determine future risk reduction benefits of a hazard mitigation project and compares those benefits to its costs. This results in a Benefit-Cost Ratio (BCR). A project is considered cost-effective when the BCR is 1.0 or greater. FEMA applicants must use agencyapproved methodologies and tools - such as the BCA Toolkit - to demonstrate the cost-effectiveness of their projects.

\section{QUUseful NIST Resources}

Guide Brief 3 - Existing Community Resilience Activities Identifying Solutions to Address Resilience Gaps: https://nvlpubs.nist.gov/nistpubs/SpecialPublications/NIST.SP.1190GB-3.pdf

Guide Brief 8 - Overcoming Myths about Community Resilience Planning: https://nvlpubs.nist.gov/nistpubs/SpecialPublications/NIST.SP.1190GB-8.pdf

Guide Brief 13 - Resilience Gaps - Identifying and Prioritizing Closure of Resilience Gaps: https://nvlpubs.nist.gov/nistpubs/SpecialPublications/NIST.SP.1190GB-13.pdf

Economic Decision Guide Software (EDGe\$) Tool : https://www.nist.gov/services-resources/software/edge-economic-decision-guide-software-tool

Playbook tables and templates: https://www.nist.gov/el/communityresilience/community-resilience-planning-guideplaybook-templates-additional-resources 


\section{S SIEP 5: PLAN PREPARATION, REVIEW, AND APPROVAL SPELL OUT THE PLAN}

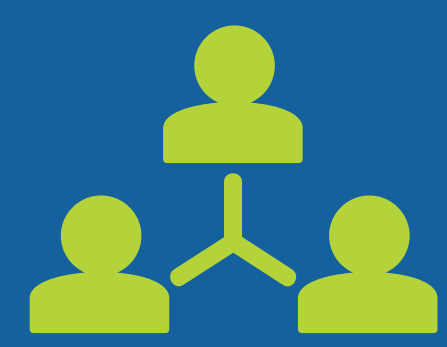

\section{Objective}

Document community resilience goals, plans, and implementation strategies with supporting information from Steps 1 through 4.

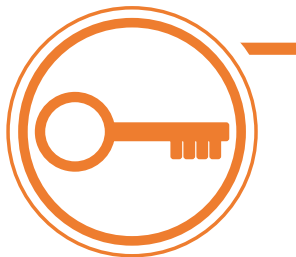

Key Take-Aways

- The adequacy, feasibility, and clarity of the plan should be key criteria for determining the level of detail needed for sharing the plan with stakeholders and the community.

- An engagement and outreach strategy should build on previous efforts to ensure that the community is aware of and understands the resilience plan and strategies, and to increase appreciation of and support for the approach.

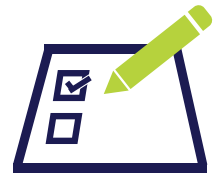

\section{Actions to Accomplish}

5-1: Document the community plans and implementation strategy.

$\square$ 5-2: Obtain feedback and approval from stakeholders and the community.

5-3: Finalize and approve the plan. 


\section{DOCUMENT THE COMMUNITY PLAN AND STRATEGY}

Action 5-1: Document the community plans and implementation strategy. The document should include enough supporting information based on work done during Planning Steps 1 through 4 to explain and justify the proposed measures. Additional back-up materials can be made available upon request to keep the plan readable.

With solutions identified and prioritized, the planning team should prepare a document to address community resilience plans, including background on how the planning process was conducted, and proposed strategies and measures to strengthen the community's resilience.

\section{WHERE AND HOW SHOULD COMMUNITY RESILIENCE GOALS AND PRIORITIES BE DOCUMENTED? (ACTION 5-1)}

A stand-alone reference document can help to unify, integrate and connect all community plans, policies, and priorities. By having community resilience goals and priorities in a separate document, they are still easily cited and any subsequent (unintended) modification that may occur if they are located in other plans is eliminated. The Guide uses community goals related to timely recovery of the community's functions to help evaluate alternative proposals and projects across all community plans.

It should include:

$>$ Community assessment of social dimensions and the built environment.

$>$ Community resilience goals and gaps in performance - setting a benchmark about where the community is and where it wants to be.

> Potential and final solutions and implementation strategies.

This document can serve as an aid to track and evaluate progress and help answer: "Is the community moving closer to its resilience goals?"

To be effective, the resilience plan should inform and complement other community planning documents. By maintaining a separate resilience plan document, key elements of the community resilience plan are retained for future reference and don't get lost as embedded information in other documents.

The "holy grail" for resilience planning is integration and alignment of community plans. This approach helps eliminate planning conflicts, increasing the likelihood that community goals can be advanced. For example, the inclusion of resilience goals within comprehensive or master plans may carry greater weight for a community than solely within a resilience or hazard mitigation plan. Integration and alignment of plans helps eliminate planning conflicts, increasing the likelihood that community goals can be advanced.

Basic guidance for preparing plans includes:

- Keep the language simple and clear.

- Summarize important information with checklists and visual aids, such as maps, flowcharts, and uncomplicated graphics.

- Avoid using jargon and minimize the use of acronyms.

- Provide enough detail to convey an easily understood plan that is actionable. 
The team should estimate the resources needed to execute the plan and indicate the likely accuracy of those estimates based on current knowledge - including an explanation of assumptions. Some solutions may require further analysis before accurate estimates can be developed, and those should be indicated. Although it is not the team's responsibility to identify funding sources for implementation at early stages, possible funding mechanisms can be identified, including proposed redirection of funding for other planned projects and increased federal funding support for mitigation efforts rather than just for post-disaster recovery.

\section{ENGAGE THE COMMUNITY TO OBTAIN FEEDBACK AND APPROVAL}

Action 5-2: Obtain feedback and approval from stakeholders and the community. Outreach should be an integral part of the team's operation from the effort's launch and should include a variety of engagement efforts.

The planning team should develop and carry out an engagement and outreach strategy to be certain that the community at large is aware of and understands the plan and to increase community-wide support.

When the plan nears readiness, team leaders should consider:

- Asking community government officials and other area governments to review the plan before it is released to the public. Involving these officials in planning and keeping them abreast of efforts along the way will improve the plan's accuracy and relevance and reduce the time required for final review. Be sure that employees of all government agencies with responsibilities under the plan are aware of and informed about the draft plan.

- Making the draft plan available for public review in electronic and print formats in readily accessible locations. Posting on public websites is highly recommended, as is leaving hard copies at the local library, government offices, etc. Accommodation may be required for special populations; for example, language or sight issues may need to be addressed so that all interested members of the community are able to review the draft and participate in the public comment process. Make the plan available in alternate formats to comply with the Americans with Disabilities Act.

Engagement and outreach options for releasing the draft plan include:

- Use social media, community online forums, and news outlets to announce the draft to the community. Support of engaged stakeholders and community influencers can help with community awareness and messaging.

- Hold one or more public meetings to present and discuss the draft plan with the community; encourage and prepare for media attendance at all public meetings. Be sure to reach all groups and members of the community. This may mean holding multiple sessions across the community, not only in government buildings.

- Special outreach activities should raise awareness and seek input from traditionally underrepresented populations.

- Arrange meetings with individual stakeholder groups whose cooperation will be vital for successful implementation of the plan. Some of these meetings may take place before the public review process begins to ensure the accuracy and relevance of the draft report.

- Ensure that employees of all government agencies with responsibilities under the plan are aware of and informed about the draft plan.

- Collect public comments, make them available to the community, and retain them as part of the project's records. 


\section{PRESENTING COMMUNITY RESILIENCE PLANS (ACTION 5-2)}

There are many ways to present the team's plans and proposed solutions and strategies. Nashua, $\mathrm{NH}$, organized resilience recommendations by hazard to address:

$>$ Local Plans and Regulations

$>$ Structure and Infrastructure Projects

$>$ Natural Systems Protection

$>$ Education and Awareness Programs

Initiatives based on the Hazard Mitigation Plan were extended to address resilience goals through:

$>$ Preparedness programs

$>$ Planning efforts

$>$ Training exercises

$>$ Social programs

$>$ Community investments

$>$ Long-term goals

Regardless of the format selected for presenting recommendations, the key is to have an easy-to-understand format and presentation. The information should address important factors, such as interdependencies and how they affect the social and economic functions of the community at the community scale.

Community meetings, forums, focus groups, facilitated online dialogues, and other forms of outreach can help to identify and promote understanding about the community goals, social needs, existing buildings and infrastructure systems, prevailing hazards, and short- and long-term benefits of the proposed solutions and actions. For short- and long-term success, transparent public collaboration and support processes are a necessity.

Expect to make changes in the plan as the larger community provides feedback. Compromises likely will be needed to reflect stakeholders' varying points of views. Vigorous discussion is often a prerequisite for, and a good indicator of, a plan that reflects a diverse community. Healthy engagement during the plan's review is more likely to lead to a plan of action that garners broad support and the level of commitment that will be needed for long-term success in improving community resilience.

\section{PLAN APPROVAL}

Action 5-3: Finalize and approve the plan. Once the community resilience plan is finalized with stakeholder and community input, the plan should be adopted formally by the community's governing body.

Formal adoption of the community resilience goals and plan helps ensure that it will influence local government activities, encourage and lay out a foundation for collaborative agreements with private owners and stakeholders, and provide a basis for implementation through local statutes or ordinances. It also establishes the authority required for changes and modifications to the plan and provides a document that can be referenced for budget-related actions that may be required in order to gain access to the necessary resources. 


\section{Objective}

Track and document the implementation of adopted strategies and solutions across community and private organizations.

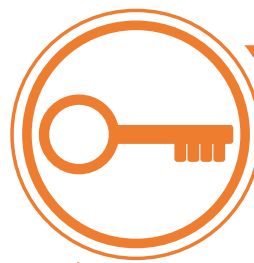

\section{Key Take-Aways}

- The community needs a designated leader who is responsible for tracking, coordinating, and communicating resilience-related efforts.

- Implementation requires continued active outreach and engagement with stakeholders and with the broader community through a variety of mechanisms.

- The adopted community plan needs to be reviewed on a regular basis, consistent with the community's planning cycles.

- The resilience plan, including the implementation strategy or specific solutions, may need to be updated.

\section{Actions to Accomplish}

$\square$ 6-1. Execute approved administrative and construction solutions.

$\square$ 6-2. Evaluate and update on a periodic basis.

$\square$ 6-3. Modify short or long-term implementation strategy to achieve performance goals as needed. 


\section{PUT THE PLAN IN MOTION}

Action 6-1: Execute approved administrative and construction solutions. Community resilience leadership should have a process and schedule for tracking implementation of adopted strategies and solutions.

A plan is only as good as its implementation. Now the heavy lifting shifts from the planning team to the government offices and private sector organizations responsible for execution. The plan should be incorporated into these organizations' priorities and related policies, plans, and programs. Continued active outreach and engagement with stakeholders, especially those involved in the plan's development and adoption, are key.

To maintain momentum and assure the plan receives the sustained attention that it will need, it is critical to designate a leader responsible for tracking, coordinating, and communicating resilience-related efforts. This can be the community resilience planning team lead, or responsibility can shift to another official. This is an important decision, and resilience must not become solely the province of an existing government function (e.g., emergency management, sustainability) to the exclusion of other functions. Nevertheless, the organizational structure selected is less important than the continuous and visible commitment to the community resilience plan. That can be demonstrated in part by the involvement of the most senior leaders of the community. However, that leadership can change, making broad community involvement even more vital.

\section{RESILIENCE LEADERSHIP THROUGH IMPLEMENTATION AND MAINTENANCE (ACTION 6-1)}

To maintain momentum and continuity and to assure that the plan receives the persistent attention that it will need, it is critical that the community designate a leader responsible for tracking, coordinating, and communicating resilience-related efforts. This can be the community resilience leader for the planning team, or the responsibility can shift to another office or official.

This demonstrates continuous and visible commitment to the community resilience plan by the senior leaders of the community.

If the six-step planning process has been followed, the plan will point to prioritized actions to be taken. Even so, additional work may be needed to organize implementation strategies in terms of responsibilities, and to coordinate the flow and timing of actions so that there is a clear road map and schedule for those charged with implementation.

In some cases, a community may decide to tackle the easier or less costly recommendations first, including administrative solutions. In another community, leaders may decide to undertake or modify at least one or more major construction project. The resources available and the timing of budgets will help to determine which actions are taken first and which will be scheduled for a later date.

Action 6-2: Evaluate and update on a periodic basis. Once adopted and implementation is underway, the community resilience plan needs to be reviewed on a regular basis, consistent with the community's planning cycles.

The planning team should recommend a process for reviewing, evaluating, and revising the plan on a recurring basis. It is also important to report regularly on sources of funding and other support, as well as challenges encountered, changing conditions, and benefits accrued over time.

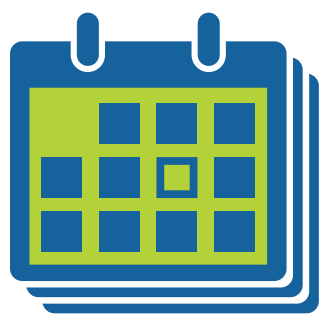




\section{KEEP THE PLAN CURRENT}

\section{Action 6-3: Modify short or long-term implementation strategy to achieve performance}

goals as needed. The planning team should monitor and communicate progress and challenges in following the implementation strategy by the community and private stakeholders.

The resilience plan, including the implementation strategy or specific solutions, may need to be modified. Triggers could be changes in the social or physical characteristics of the community, new or unexpected events, or improved understanding of the built environment and the impact of prevailing hazards. These include:

- Lessons learned while implementing the plan.

- Experience with one or more hazard events.

- Changes in operational resources (e.g., policy, personnel, organizational structures, management processes, facilities, equipment).

- Changes in federal or state government policies or programs which may offer new incentives or impose new requirements.

- Formal updating of planning guidance or standards (e.g., changes in national design standards and model codes that are beginning to incorporate the concept of "immediate occupancy" and "functional recovery" after hazard events).

- New technology or approaches that affect resilience solutions and strategies.

- Changes in elected officials.

- Major hazard-related exercises which may highlight new vulnerabilities or problems with current approaches.

- Changes in demographics, vulnerabilities, or hazard or threat profile.

- Changes in the acceptability of various risks.

- Enactment of new or amended laws or ordinances.

Improving community resilience is an ongoing process in a constantly shifting social, political, and physical environment. It truly is a marathon rather than a sprint. Others say it is a way of thinking, a way of life. Developing and carrying out a comprehensive resilience plan that takes into account the community's goals - and the way in which its people and institutions rely on the interdependent built environment - will go a long way toward improving the quality of life in the community.

\section{Q'Useful NIST Resources}

Guide Brief 12 - Short-Term Implementation Tasks:

https://nvlpubs.nist.gov/nistpubs/SpecialPublications/NIST.SP.1190GB-12.pdf

Playbook tables and templates:

https://www.nist.gov/el/communityresilience/community-resilience-planning-guide-playbook-templates-additionalresources 
Disclaimer: Certain commercial entities, equipment, or materials may be identified in this document in order to describe an experimental procedure or concept adequately. Such identification is not intended to imply recommendation or endorsement by the National Institute of Standards and Technology, nor is it intended to imply that the entities, materials, or equipment are necessarily the best available for the purpose.

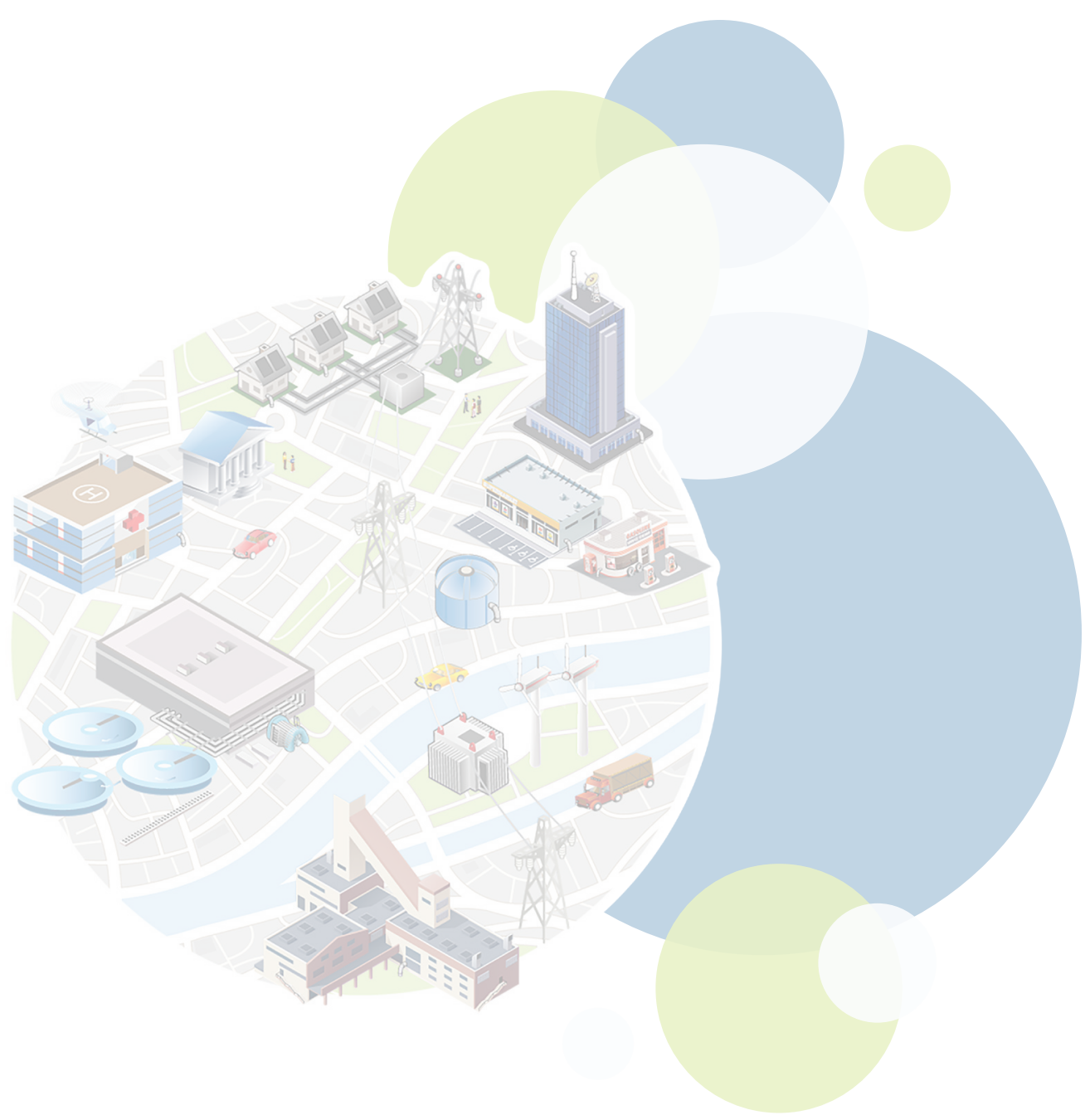

